Article

\title{
Risk Identification and Analysis for PPP Projects of Electric Vehicle Charging Infrastructure Based on 2-Tuple and the DEMATEL Model
}

\author{
Lihui Zhang ${ }^{1,2}$, Zhenli Zhao ${ }^{1,2, * \mathbb{D}}$, Jianxue Chai ${ }^{1,2}$ and Zhinan Kan ${ }^{3}$ \\ 1 School of Economics and Management, North China Electric Power University, Hui Long Guan, \\ Chang Ping District, Beijing 102206, China; zlh6699@126.com (L.Z.); chaijianxue1@126.com (J.C.) \\ 2 Beijing Key Laboratory of New Energy and Low-Carbon Development, North China Electric Power \\ University, Hui Long Guan, Chang Ping District, Beijing 102206, China \\ 3 Luneng New Energy (Group) Co., Ltd., Beijing 100000, China; kanzhinan@163.com \\ * Correspondence: 1172106006@ncepu.edu.cn; Tel.: +86-150-1098-3996
}

Received: 24 December 2018; Accepted: 11 January 2019; Published: 16 January 2019

\begin{abstract}
Risk management is critical to the success of electric vehicle charging infrastructure public-private partnership (EVCI-PPP) projects, as risks are present throughout the whole life cycle of projects. However, in EVCI-PPP projects, risk factors are often interdependent and, consequently, the interrelationships among factors affect the risk management, which is ignored in the existing studies. To identify the risk factors of EVCI-PPP projects and analyze their internal influence relations, this paper develops a risk identification and analysis model of EVCI-PPP projects based on the 2-tuple linguistic representation model and the decision-making trial and evaluation laboratory (DEMATEL) model. First, a risk factor set is established including 22 criteria involved in 5 dimensions of political/legal risk, economic/market risk, social/environment risk, project/technical risk, and managing risk. Next, the 2-tuple model is introduced to integrate the decision makers' evaluation information in a linguistic environment, and the direct relation matrix is calculated. Then, the cause-effect relations and a significant degree of risk factors are interpreted using the extended DEMATEL technique. The results show that economic/market risk is the most significant factor of EVCI-PPP projects, and 22 criteria are classified into 14 cause factors and 8 effect factors. Finally, suggestions are provided for decision-makers to ensure the success of EVCI-PPP projects.
\end{abstract}

Keywords: electric vehicle charging infrastructure PPP project; risk identification and analysis; 2-tuple; decision making trial and evaluation (DEMATEL) model

\section{Introduction}

Electric vehicles (EVs) have been considered a promising technology for mitigating greenhouse gas (GHG) emissions, which have attracted the attention of countries all over the world [1,2]. In 2017, the global market share of new energy vehicles exceeded 1 million on the road. As the largest market of electric cars in terms of sales share, China has sold 556,000 electric cars, accounting for 50\% globally [3]. As an essential component of supply infrastructure, public charge piles totaled 214,000 in 2017, as shown in Figure 1. However, it is worth noting that the imbalance of demand-supply in electric vehicle charging infrastructure (EVCI) and low charging service have become the prominent obstacles to sustainable development of EVs in China [4]. To deal with the issues mentioned, the public-private partnership (PPP) model has been introduced in EVCI projects to satisfy increasingly urgent charging demand by attracting private sectors to participant in electric vehicle charging infrastructure public-private partnership projects (EVCI-PPPs) [5,6]. EVCI-PPPs have the following advantages: (1) they release the government's financial pressure and management pressure; (2) they make use of the private sectors' 
strengths in financing, construction, operation, and management; and (3) they provide satisfactory, efficient, and diverse charging services, which are beneficial to promote the sustainable development of EVs and EVCI projects.

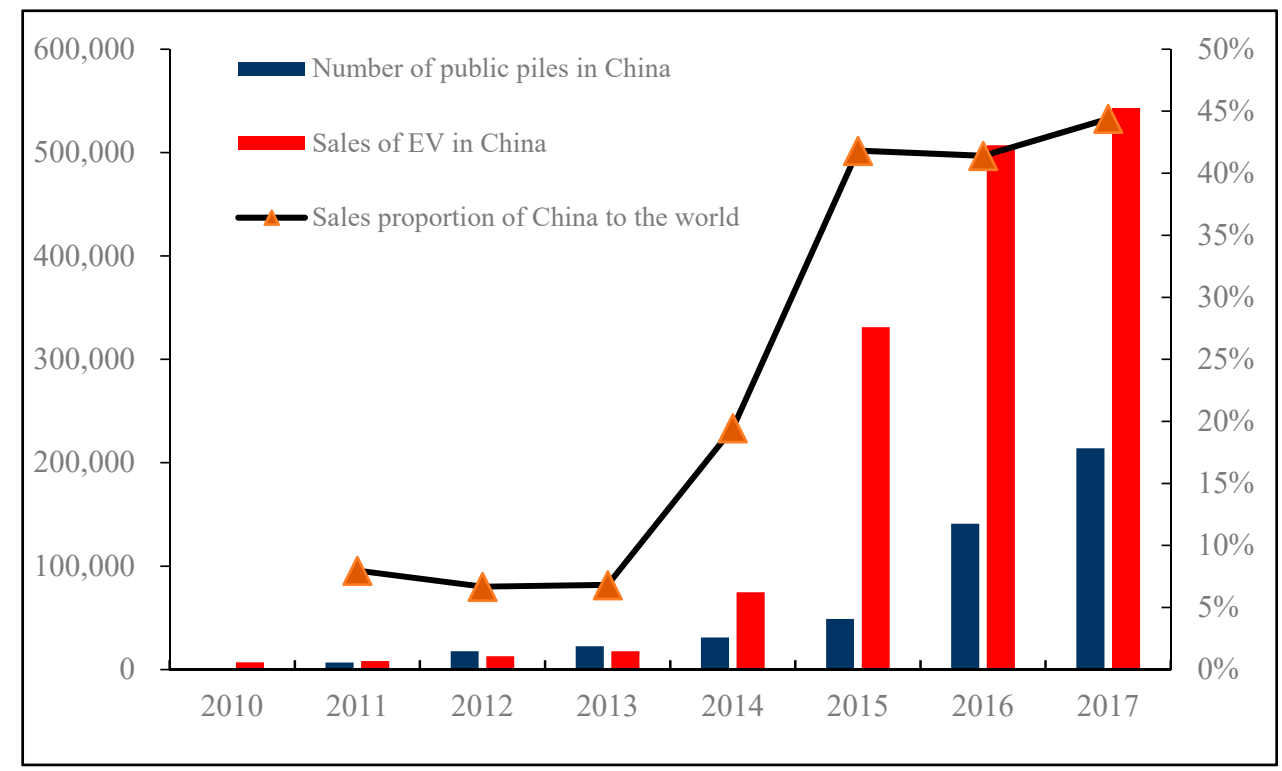

Figure 1. The number of electric vehicles (EVs) and public charging infrastructure in China.

In 2015, the first batch of China's EVCI-PPP projects appeared, and by 2018, 17 EVCI-PPP projects had been approved. However, there are only a few completed projects and most are still in the preparatory or identification stage. The inherent characteristics of PPP projects-large-scale investment, long-term of construction and operation, and complex construct structure-increase the uncertainty of risks in the whole life of projects [7]. In EVCI-PPPs, the identification of risk factors is the core of full risk management. In the real world, risk elements are always interdependent and the interrelationships may strengthen the transmission effect from one risk factor to another, bringing the domino effect. Therefore, it is necessary to consider the interrelationships among risk factors in risk identification of EVCI-PPP projects, which could support the stakeholders to make the right decisions and take targeted risk control measures.

The charging infrastructure industry is at a nascent stage and research on the risk identification of charging infrastructure projects is limited [8]. Currently, there are three points focused on charging infrastructure: (i) site selection of charging facilities [9]; (ii) business model for charging infrastructure [10,11], the PPP model [3]; and (iii) incentive industry policies [12-14]. Although the PPP model is viewed as an effective means to promote the sustainable development of charging facilities [5], the EVCI-PPP project is in the initial stages in China and faces various uncertain risks. The authors of [15] identified risk factors and determined the risk level of specific projects from the view of social investors. The authors of [16] conducted risk management of EVCI-PPP projects. However, they did not discuss the relationship of each risk factor in depth, and neglecting the relationship among risk factors will cause a serious domino effect.

This paper aims to do the following: (1) identify risk criteria of EVCI-PPP projects from the view of the whole life of projects; (2) classify all risk criteria into cause and effect groups; (3) distinguish the interrelationship and draw a cause-effect diagram among dimensions and criteria; and (4) calculate the significant degrees of each risk factor.

The reminder of this paper is organized as follows. Section 2 reviews the risk factors of the EVCI-PPP project and interprets the DEMATEL technique. Section 3 builds a risk factor set of EVCI-PPP projects. A risk identification and analysis model is established in Section 4. Section 5 presents the data analysis and results of this paper. Section 6 discusses the classification of risk factors, and Section 7 provides some suggestions. Finally, the conclusions and further work are shown in Section 8. 


\section{Literature Review}

\subsection{Risk Analysis of EVCI-PPP Projects}

As a novel financing model, PPP has been successfully applied in charging infrastructure and scholars have achieved some research findings. The authors of [17] pointed out that the PPP model can reduce the financial burden of the government and stimulate innovation of business model for charging facilities. The authors in [6] believed that the introduction of the PPP model into charging facilities could make use of private investors to improve the management and profitability of projects. The authors in [5] illustrated that the PPP model is an effective way to enhance charging service efficiency.

In PPP projects, risk management is an important topic, and factor identification is a critical phase in the risk management process. The authors in [15] developed a framework to identify the most important risk factors influencing EVCI-PPP projects in China, and to evaluate the overall risk level of PPP projects. However, it remains in the risk assessment stage, lacking comprehensive risk management. To fill this gap, the authors in [16] proposed a three-dimensional model to control risks in EVCI-PPP projects. These findings provide comprehensive risk management for the decision makers. However, the existing research neglects the interrelationships among risk criteria when identifying and analyzing risk factors, which also has a significant influence on risk management.

At present, key risk factors associated with public-private partnerships have been identified by multiple scholars in other areas. In another paper [18], public opposition, insufficient supply risk, and improper operation were viewed as the top three risk factors in waste-to-energy incineration PPP projects. The authors of [19] carried out risk allocation in PPP projects in China. The authors in [20] drew a conclusion that insufficient supply, deals with non-licensed resources, environmental risk, payment risk, and lack of supporting facilities are the five critical risk factors. Table 1 shows some critical risk criteria in PPP projects from representative studies, which provides us with methodological guidance and indicator reference.

This paper aims to study the influence relations among risk factors of EVCI-PPP projects from the view of the system. On the basis of the literature review, opinions of experts and industrial managers, risk elements, associated with PPP projects, are recognized and identified. A risk evaluation index system is established, which consists of five dimensions in the first step-political/legal risk, economic/market risk, social/environmental risk, project/technical risk, and managing risk. The risk factors attributed to those criteria will be discussed in Section 3 .

Table 1. Summary of selected literature on risks/barriers to public-private partnership (PPP) infrastructure projects.

\begin{tabular}{|c|c|c|c|c|c|c|c|c|c|c|c|c|}
\hline \multirow{2}{*}{ No. } & \multirow{2}{*}{ Risk Factors } & \multicolumn{10}{|c|}{ Reference } & \multirow{2}{*}{ Total } \\
\hline & & 1 & 2 & 3 & 4 & 5 & 6 & 7 & 8 & 9 & 10 & \\
\hline 1 & Unstable government & & & & & & * & & & & * & 2 \\
\hline 2 & Government corruption & * & & * & * & & * & * & * & * & & 7 \\
\hline 3 & Government intervention & * & * & * & & & * & * & * & * & & 7 \\
\hline 4 & Government credit & & * & * & * & * & * & * & & * & & 7 \\
\hline 5 & Poor public decision-making process & * & & & * & * & * & * & * & * & * & 8 \\
\hline 6 & Delays in approval and permits & & * & & * & & * & & * & & * & 5 \\
\hline 7 & Inadequate distribution of responsibilities and risk & & & & & & * & & & * & * & 3 \\
\hline 8 & Lack of a sound legal framework & & & & & & & * & * & & & 2 \\
\hline 9 & No supportive legislations and policies & * & & & & * & & & & & & 2 \\
\hline 10 & Legislation change & & * & & * & & * & * & * & & & 5 \\
\hline 11 & Land acquisition/site availability & & * & & * & & * & * & * & & * & 6 \\
\hline 12 & Insufficient goods supply & * & * & & & & & & & & * & 3 \\
\hline 13 & Market demand change & & * & * & * & & & * & * & & & 5 \\
\hline 14 & Financial risk & & * & & * & & * & * & * & & * & 6 \\
\hline 15 & Payment risk & * & * & * & * & * & * & * & & & & 7 \\
\hline 16 & Inflation risk & & * & & * & & * & & * & & * & 5 \\
\hline 17 & Interest rate volatility & & & * & * & & * & * & * & & * & 6 \\
\hline
\end{tabular}


Table 1. Cont.

\begin{tabular}{|c|c|c|c|c|c|c|c|c|c|c|c|c|}
\hline \multirow{2}{*}{ No. } & \multirow{2}{*}{ Risk Factors } & \multicolumn{10}{|c|}{ Reference } & \multirow{2}{*}{ Total } \\
\hline & & 1 & 2 & 3 & 4 & 5 & 6 & 7 & 8 & 9 & 10 & \\
\hline 18 & Revenue risk & * & & * & & * & * & & & & & 4 \\
\hline 19 & Environment risk & * & * & & & * & * & * & & & * & 6 \\
\hline 20 & Public opposition & * & & & * & * & * & & * & & * & 6 \\
\hline 21 & Construction time delay & & & & & & * & & * & & * & 3 \\
\hline 22 & Design \& construction deficiencies & & & & & & * & & * & & * & 3 \\
\hline 23 & Completion risk & & * & & * & & * & * & & * & * & 6 \\
\hline 24 & Lack of PPP experience & * & & * & & & & & * & & * & 4 \\
\hline 25 & Overrun of construction cost & & & & & & * & & * & & * & 3 \\
\hline 26 & Overrun of operation cost & & * & & * & & * & * & & & * & 5 \\
\hline 27 & Technique risk & * & & & * & * & * & & * & & * & 6 \\
\hline 28 & Supporting facilities risk & * & * & * & * & * & * & * & * & & & 8 \\
\hline 29 & Lack of commitment from either partner & & & & & & * & & & * & * & 3 \\
\hline 30 & Insufficient financial audit & & & & * & & * & * & & & & 3 \\
\hline 31 & Force majeure & & * & & * & & * & * & * & & & 5 \\
\hline
\end{tabular}

Notes: $1=[18] ; 2=[20] ; 3=[15] ; 4=[19] ; 5=[21] ; 6=[22] ; 7=[23] ; 8=[24] ; 9=[25] ; 10=[26]$.

\subsection{DEMATEL Method}

This paper extracts important risk factors in EVCI-PPP projects in Section 2.1, and these factors influence each other. To make progress in charging infrastructure projects, the influence relations among risk factors should be considered to conduct a comprehensive risk analysis. The decision making trial and evaluation laboratory (DEMATEL) technique is effective to handle this issue [27], which integrates the experts' evaluation information, and illustrates the interrelationship among risk factors and the significant degree of all factors based on a cause-effect diagram [28].

The DEMATEL technique has been widely applied in various fields [29,30], for example, critical factors identification, information management, and risk management. However, this method cannot deal with the fuzziness of linguistic information in assessment. The authors in [31] developed DEMATEL to conclude the influencing and influenced distress of sewer pipelines. Meanwhile, there are many studies involving innovated DEMATEL models combined other multi-criteria decision methods. The authors in [32] proposed a newly extended 2-tuple and DEMATEL model to evaluate the risks of IT outsourcing and compute the importance, as well as the classification, of risk factors. The authors of [33] estimated the elements of $\mathrm{CO}_{2}$ capture and storage in the iron and steel industry based on the integrated 2-tuple DEMATEL method.

In general, DEMATEL is an effective tool to handle barriers and risk elements. 2-tuple can effectively retain expert evaluation information and reduce information loss in processing expert linguistic decisions. Moreover, the combined method of 2-tuple and DEMATEL has no loss of evaluation information when computing with linguistic terms, which can deal with complex problems and establish visualization of a cause-effect diagram. Therefore, this paper develops the model based on the 2-tuple fuzzy linguistic representation model and DEMATEL model to identify and analyze the risk factors of EVCI-PPP projects, obtain the weights of each criterion, classify important criteria into cause and effect groups, and depict the cause-effect diagram to visualize the influence interrelationships among risk factors.

\section{Risk Factors of EVCI-PPP Projects}

EVCI-PPP projects are recognized as risky investments and are characterized by large initial investment, administrative difficulties, low charge utilization, and poor charge efficiency. From literature reviews, the risk factors of EVCI-PPP projects are identified, which includes 22 risk factors from 5 dimensions (see Figure 2), presented below. 


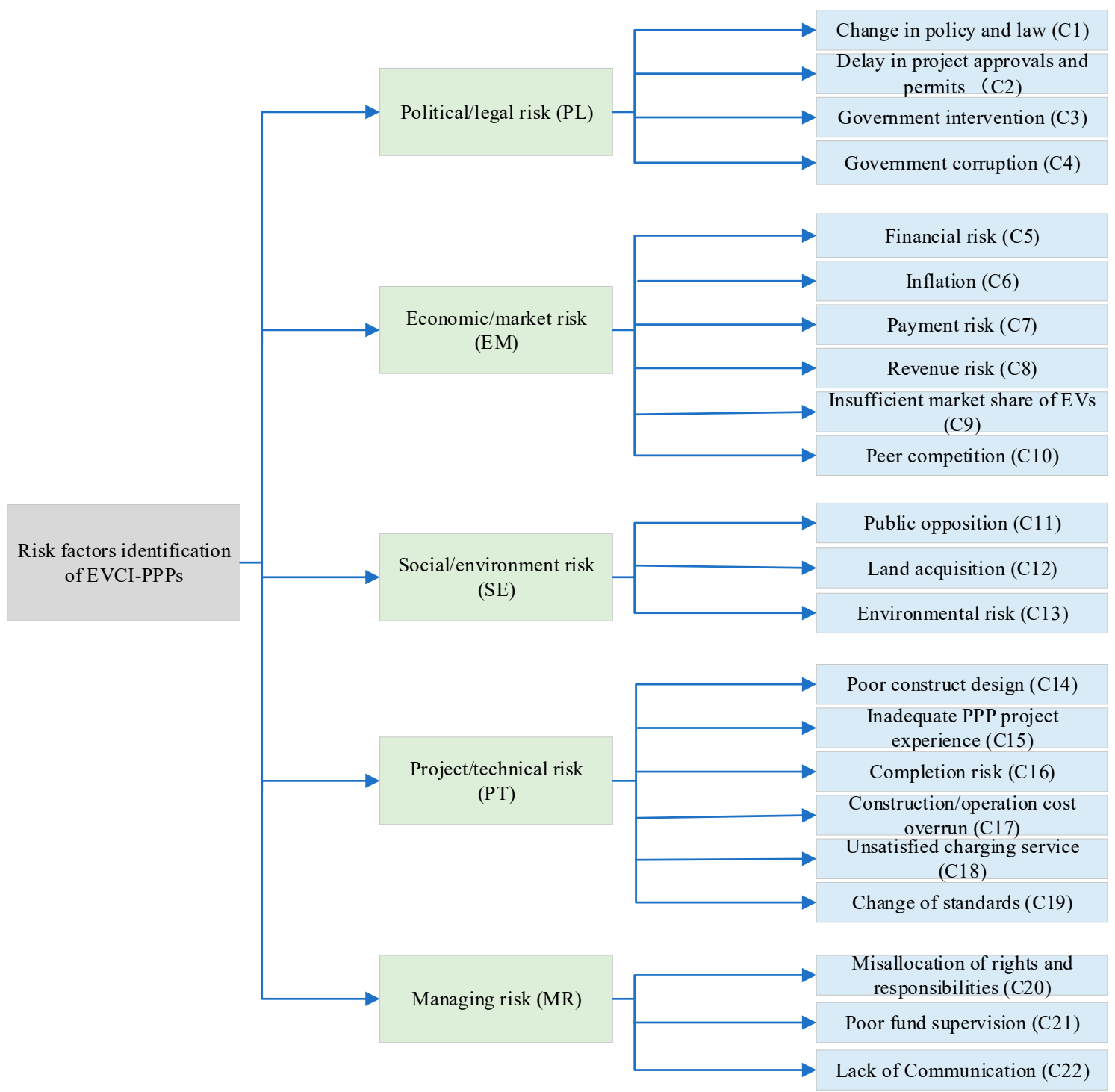

Figure 2. The risk factors of electric vehicle charging infrastructure public-private partnerships (EVCI-PPPs) in China.

\subsection{Political/Legal Risk (PL)}

To encourage private investors to participate in the operation of EVCI-PPP projects, regional governments have introduced various incentive policies to create a good political environment for partnership [34]. For example, Hainan province in China has incorporated the approval of charging facilities into the green approval channel, which simplified the approval process and shortened the approval time. On the contrary, China has retreated 30 PPP projects to curb the increasing implicit debt in 2018, which means the regulations of the PPP model will be stricter. Some regions strengthen the approval and review process to prevent excessive government debt. Changing policies and various rules increase the risk of EVCI-PPP projects.

C1: Change in policy and law. In China, the development of charging infrastructure is profit from incentive policies. However, EVCI-PPP projects have a short history in China. It is inevitable that industrial policies will change, even the current political environment is positive to advance the PPP model to deliver charging service and infrastructure [35]. 
C2: Delay in project approvals and permits. This mainly refers to the fact that the permit process is too complicated and the government lacks PPP experience to deal with this issue, which causes lower permit efficiency and affects a series of risks of PPP projects [24].

C3: Government intervention. This risk refers to government over-intervention EVCI-PPP projects by macroeconomic or administrative means, such as requiring private operators to recruit residents as employees, which may affect the normal business operation of PPP projects [36].

C4: Government corruption. The risk factor of government corruption refers to government officials obtaining property illegally, and private investors having spend large sums of money to get access to local officials, which not only disturbs the normal market competition, but also hampers concessionaires' operation efficiency, as well as profits [37].

\subsection{Economic/Market Risk (EM)}

Fluctuation in the economic market, for example, inflation and interest rates, may increase financing risks and revenue risks. Because of the long period, each private operator faces high economic and market risk [38].

C5: Financial risk. Insufficient funds and change of interest rate directly affect the construction of projects. In general, PPP projects require a large investment and social sectors usually obtain a loan from banks, and the change of interest rate increases the financing risks [39].

C6: Inflation. A rise in the price level will decline the purchasing power of money and increase staff cost and materials prices, increasing construction and operating costs. In EVCI-PPPs, private sectors reduce the influence of inflation risk by adjusting the charge price, which also increases charge services [40].

C7: Payment risk. This risk refers to the government possibly not being willing to pay for private sectors in time. Where payment is not guaranteed, the private operator may withdraw [20].

C8: Revenue risk. This risk means that the profits are lower than the anticipated revenue. In EVCI-PPPs, the current market price is still lower than the real cost in public charging services. Operators may reduce the service quality or increase charge fees to compensate for the loss, which deviates from the original intention of introducing the PPP model [19].

C9: Insufficient market share of EVs. Currently, the market share of new energy vehicles is not enough to meet the normal charging needs of charging stations [41].

C10: Competition. This refers to threats from other public charging projects and private charging piles. There are multiple entities in the current charging facility market, which is undesirable because of the uniqueness of the PPP projects. In general, EV users are willing to conduct major charging at their home in the evening because of the low charging price and convenience. Thus, the development of private charging piles will affect the competitiveness and benefits of public charging facilities [42].

\subsection{Social/Environment Risk (SE)}

EVCI-PPP projects may generate noise and dust during the construction process. At the same time, improper sites of charging stations may have negative effects on approvals, completion of projects, traffic congestion, and the layout of cities' traffic network.

C11: Public opposition. This risk arises from the opposition from the public because of improper site selection, environmental pollution, and security concerns [43].

C12: Land acquisition. Land acquisition risk concerns both land acquisition and demolishing existing buildings. This risk generally occurs in prosperous urban areas, such as commercial areas and residential areas. The high acquisition cost or duty dereliction of government may cause failure of PPP projects [44].

C13: Environment risk. Environmental pollution, such as noise and dust during the construction stage, will bring negative effects to the EVCI-PPP projects [45]. 


\subsection{Project/Technical Risk (PT)}

Charging technology has been in the process of upgrading and concessionaires faces the risk of technology limitations [46].

C14: Poor design. Improper site selection and layout of charging stations are adverse to charging volume, as well as the operation of charging facilities [47].

C15: Inadequate PPP project experience. PPP projects are still in the initial stage in China, and the application of the PPP model in charging facilities has a short history. Both the government and the concessionaire have inadequate PPP project experience in operation, management, and so on [36].

C16: Completion risk. This refers to risk that the project cannot be completed in the planned period because of insufficient staff, financial difficulties, inadequate experience, and so on [48].

C17: Construction/operation cost overrun. This means that actual costs are higher than expected because of changes in the economic and political environment, taxes, and aging of equipment [49].

C18: Unsatisfactory charging service. This refers to the charging service quality and efficiency being unable to satisfy EV drivers' demand, which directly affects the revenue of EVCI-PPP projects [15].

C19: Charging technology. The supply power way includes direct current (DC), alternating current (AC), wireless charging, and power exchange. Currently, fast charging technology is hitherto explored research-wise and the standards of charging interface and charging facilities are also being upgraded. The immature technology of charging requires improvement of devices, which increases the investments of projects [50].

\subsection{Managing Risk (MR)}

EVCI-PPP projects combine the advantages of the government and private sectors. The government provides a sound environment for PPP projects by political and economic measures, and the concessionaire relies on their advanced management experience and operation mechanisms. Only cooperation can avoid various risks and achieve a win-win situation in EVCI-PPP projects.

C20: Misallocation of rights and responsibilities. Contracts vaguely define responsibilities and obligations, as well as lack of consistency, which causes alteration and shirks their responsibility of the government and concessionaire [22].

C21: Poor fund supervision. Inadequate fund supervision may make the government lose control over the use of funds in PPP projects, which will cause indiscriminate usage of funds and subsidies [23].

C22: Lack of communication. PPP stakeholders are committed to a long-term relationship with each other, and communication is an effective way to maintain this relationship. Poor communication between the government and the social sectors hampers decision making and successful operation of PPP projects [51].

\section{Methodology}

\subsection{The Definition and Aggregation Operator of the 2-Tuple Linguistic Information}

In Section 4.1, basic concepts and operations on the 2-tuple linguistic representation model are performed. Proposed by Herrera in 2000 [52], 2-tuple is based on the concept of symbolic translation. It uses a 2-tuple set, $\left(S_{i}, \alpha_{i}\right)$, to demonstrate linguistic evaluation information, where $S_{i}$ is the symbolic translation of a linguistic term; $\alpha_{i}$ is a numerical value of the symbolic translation; and $\alpha_{i} \in[-0.5,0.5)$, indicating the deviation of the evaluation result from $S_{i}$.

Definition 1. Let $S=\left\{S_{0}, S_{1}, S_{2}, \cdots, S_{\delta}\right\}$ be a linguistic term set, amount of $S_{i} \in S$. The function $\beth$ used to perform the corresponding 2-tuple of $S_{i}$ is obtained as follows:

$$
\beth=S \rightarrow S \times[-0.5,0.5)
$$




$$
\beth\left(S_{i}=\left(S_{i}, 0\right), S_{i} \in S\right.
$$

Definition 2. Let $S=\left\{S_{0}, S_{1}, S_{2}, \cdots, S_{\delta}\right\}$ be a finite and totally ordered discrete linguistic term set. And $\beta \in[0, \delta]$ is a number value, representing a symbolic linguistic aggregation result. The 2-tuple that presents the equivalent information to $\beta$ can be computed by the function $\nabla$.

$$
\begin{gathered}
\nabla:[0, \delta] \rightarrow S \times[-0.5,0.5) \\
\nabla(\beta)=\left(S_{i}, \alpha\right)=\left\{\begin{array}{c}
S_{i}, \quad i=\operatorname{Round}(\beta) \\
\alpha=\beta-i . \quad \alpha \in[-0.5,0.5)
\end{array}\right.
\end{gathered}
$$

where round is the usual round operation.

Definition 3. Let $\left(S_{i}, \alpha\right)$ be a 2-tuple, and assume that there is an inverse function $\nabla^{-}$, which is used to transform the 2-tuple into its corresponding numerical value $\beta \in[0, \delta]$. The function $\Delta^{-}$is defined as Equations (3a) and (3b).

$$
\begin{gathered}
\nabla^{-}: S \times[-0.5,0.5) \rightarrow[0, \delta] \\
\nabla^{-}\left(S_{i}, \alpha\right)=i+\alpha=\beta
\end{gathered}
$$

Definition 4. Let $\left(D_{1}, \alpha_{1}\right),\left(D_{2}, \alpha_{2}\right), \cdots,\left(D_{m}, \alpha_{m}\right)$ be a group of 2-tuples to be aggregated. The 2-tuple arithmetic mean operator $\bar{D}^{e}$ is defined as follows:

$$
\bar{D}^{e}=(\bar{D}, \bar{\alpha})=\nabla\left(\frac{1}{m} \sum_{i=1}^{m} \nabla^{-}\left(D_{i}, \alpha_{i}\right)\right), \bar{D} \in S ; \bar{\alpha}=[-0.5,0.5)
$$

Definition 5. Let $F=\left(\left(r_{1}, \alpha_{1}^{\prime}\right),\left(r_{2}, \alpha_{2}^{\prime}\right), \cdots,\left(r_{m}, \alpha_{m}^{\prime}\right)\right)^{T}$ be the corresponding weighted vector of 2-tuples $\left(D_{1}, \alpha_{1}\right),\left(D_{2}, \alpha_{2}\right), \cdots,\left(D_{m}, \alpha_{m}\right)$. The 2-tuple weighted average operator $\hat{D}^{e}$ is defined as follows:

$$
\hat{D}^{e}=(\hat{D}, \hat{\alpha})=\nabla\left(\frac{\sum_{I=1}^{m}\left[\nabla^{-}\left(r_{i}, \alpha_{i}^{\prime}\right) \times \nabla^{-}\left(D_{i}, \alpha_{i}\right)\right]}{\sum_{i=1}^{m} \nabla^{-}\left(r_{i}, \alpha_{i}^{\prime}\right)}\right), \hat{D} \in S ; \hat{\alpha} \in[-0.5,0.5]
$$

\subsection{The 2-Tuple DEMATEL Method}

Between 1972 and 1976, the DEMATEL was proposed, and it has been proven as an effective approach for analyzing interrelationships among factors [53]. Based on digraph theory, the DEMATEL method performs well in analyzing the cause and effect in a system by classifying factors. In this research, a modified 2-tuple DEMATEL model is developed to identify the importance and classification of risk criteria and to build the cause-effect diagram. The framework of the risk analysis model is shown in Figure 3. 


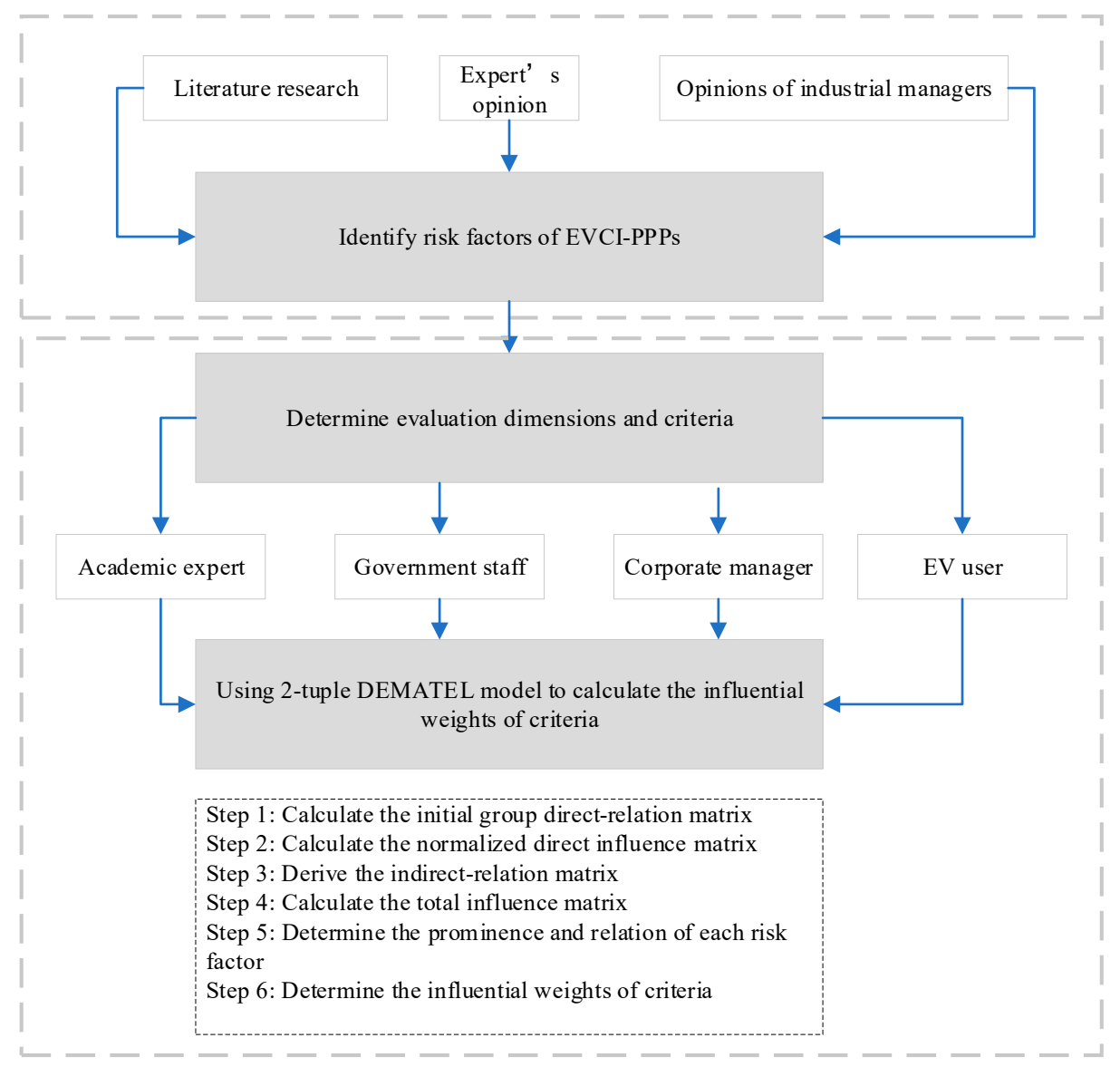

Figure 3. The procedure of the risk analysis model based on 2-tuple decision-making trial and evaluation laboratory (DEMATEL).

The formulating steps of the classical DEMATEL technique are described below [54].

\section{Step 1: Calculate the direct-relation matrix.}

Let $C=\left\{c_{1}, c_{2}, \cdots, c_{n}\right\}$ be a risk factors set, $c_{j}$ be the $j$ th criteria, $j=1,2, \cdots, n . \quad E=$ $\left\{e_{1}, e_{2}, \cdots, e_{K}\right\}$ is an experts' decision set, $e_{K}$ is the $k$ th expert, $k=1,2, \cdots, K$. In this step, each expert uses a five level scale to rate the risk factors and form a direct relationship matrix.

$$
\begin{gathered}
\mathrm{S}=\left\{s_{0}=\text { No influence }(\mathrm{NO}), s_{1}=\text { Very low influence }(\mathrm{VL}), s_{2}=\text { Low influence }(\mathrm{L}),\right. \\
\left.s_{3}=\text { High influence }(\mathrm{H}), s_{4}=\text { Very high influence }(\mathrm{VH})\right\} .
\end{gathered}
$$

On the basis of this function, defined by Equations (1) and (2), initial direct-relation matrices, $Z_{k}=\left[z_{i j}^{k}\right]_{n \times n^{\prime}}$ are transformed into $\hat{Z}_{k}=\left[\hat{z}_{i j}^{k}\right]_{n \times n^{\prime}}, \hat{z}_{i j}^{k}=\left(z_{i j}^{k}, 0\right), k=1,2, \cdots, m, i, j=1,2, \cdots, n$. The group direct-influence matrix can be computed by using the 2-tuple arithmetic mean operator as Equation (6).

$$
\hat{z}_{i j}=\left(z_{i j}, \alpha_{i j}\right)=\nabla\left(\frac{1}{k} \sum_{k=1}^{K} \nabla^{-1}\left(z_{i j}^{k}, 0\right)\right)
$$

where $z_{i j} \in S, \alpha_{i j} \in[-0.5,0.5), i, j=1,2, \cdots, n$ 


\section{Step 2: Compute the normalized direct-influence matrix.}

The normalized direct-relation matrix $\mathrm{X}=\left[x_{i j}\right]_{n \times n}$ is computed as follows:

$$
x_{i j}=\frac{\Delta^{-1}\left(z_{i j}, \alpha_{i j}\right)}{s}
$$

where $\mathrm{s}=\max \left\{\max _{1 \leq i \leq n} \sum_{j=1}^{n} \nabla^{-1}\left(z_{i j}, \alpha_{i j}\right)\right\}, 0 \leq x_{i j} \leq 1, i, j=1,2, \cdots, n$.

There is at least one element $i$ in the matrix $\mathrm{X}$ to let the following inequality exist:

$$
\sum_{j=1}^{n} \nabla^{-1}\left(z_{i j}, \alpha_{i j}\right) \leq s
$$

\section{Step 3: Derive the indirect-relation matrix.}

According to essential ideas of DEMATEL, indirect-relation matrix $\mathrm{H}$ can be derived as follows:

$$
\mathrm{H}=\lim _{\tau \rightarrow \infty}\left(X^{2}+\cdots+X^{\tau}\right)=X^{2}(I-X)^{-1}
$$

where $I$ is the identity matrix.

\section{Step 4: Generate the total relation matrix.}

On the basis of $X=\left[x_{i j}\right]_{n \times n}$ and $H=\left[h_{i j}\right]_{n \times n^{\prime}}$ an overall-relation matrix $T=\left[t_{i j}\right]_{n \times n}$ is generated by Equation (9).

$$
t_{i j}=x_{i j}+h_{i j}, \quad i, j=1,2, \cdots, n .
$$

where $t_{i j}$ is the overall intensity of the direct and indirect interrelationship between $c_{i}$ and $c_{j}$.

\section{Step 5: Obtain the prominence and relation of each risk criteria.}

In this step, the influence degree $r$ - the sum of rows - and the degree of being influenced $c$ - the sum of columns-can be determined based on Equations (10) and (11).

$$
\begin{aligned}
& r=\left[r_{i}\right]_{n \times 1}=\left(\sum_{j=1}^{n} t_{i j}\right)_{n \times 1^{\prime}}, i=1,2, \cdots, n \\
& c=\left[c_{j}\right]_{n \times 1}=\left(\sum_{i=1}^{n} t_{i j}\right)_{1 \times n^{\prime}}^{T} j=1,2, \cdots, n
\end{aligned}
$$

Let $P_{i}$ denote the prominence of risk factors $c_{i}$, which represents the importance of risk factor $c_{i}$. $P_{i}$ is calculated by Equation (12).

$$
P_{i}=r+c=\sum_{j=1}^{n} t_{i j}+\sum_{i=1}^{n} t_{i j}
$$

Let $R_{i}$ denote the relation of risk factor $c_{i}$. Here, $R_{i}$ is expressed as Equation (13).

$$
R_{i}=r-c=\sum_{j=1}^{n} t_{i j}-\sum_{i=1}^{n} t_{i j}
$$

where $i, j=1,2, \cdots, n$.

Through the value of $R_{i}$, we can judge where risk factor $c_{i}$ is a cause risk factor or an effect risk factor. If $R_{i}>0, c_{i}$ is a cause risk factor, which indicates the factor influences other criteria. On the contrary, $R_{i}<0, c_{i}$ is an effect risk factor, which is easily influenced by other risk factors.

On the basis of prominence $P_{i}$, horizontal axis, and relation $R_{i}$ vertical axis, $i=1,2, \cdots, n$, a cause-effect diagram can be constructed to visualize the importance and classification of overall risk 
criteria. According to this cause-effect diagram, the government and private decision makers could take target measures to control EVCI-PPP projects' risk.

\section{Step 6: Determine the influential weights of criteria.}

The relative importance of the risk factors can be determined by Equation (14).

$$
w_{j}=\left[\left(P_{i}+R_{i}\right)^{2}+\left(P_{i}-R_{i}\right)^{2}\right]^{\frac{1}{2}}
$$

The weight of any criterion can be normalized by Equation (15).

$$
\overline{w_{j}}=\frac{w_{j}}{\sum_{j=1}^{n} w_{j}}
$$

where $\overline{w_{j}}$ is the final weights of risk factor $c_{i}$. Consequently, the influential weight of each risk factor could be obtained by the modified 2-tuple DEMATEL method. Moreover, decision makers can control risk and take targeted measures based on the weights of risk criteria.

\section{Data Analysis and Results}

To identify and analyze the risk factors of EVCI-PPP projects, significant literature research related to risk management of PPP projects was conducted, and four decision makers (denoted by D1, D2, D3, and D4) were invited to give the direct impact of each factor on others; the backgrounds of the decision makers are shown in Table 2. This decision makers group involves a government official, an academic expert, a construction company manager, and an EV user. They have studied in the PPP field for more than five years, and the EV user has been a frequent user of EV services for a long time. On the basis of their extensive working experience, a linguistic term of the first level is obtained, as illustrated in Table 3.

Table 2. Background of decision makers.

\begin{tabular}{ccc}
\hline Decision Maker & Department & Work Experience \\
\hline D1 & China Public Private Partnerships Center & 8 \\
D2 & North China Electric Power of University & 12 \\
D3 & TGOOD & 10 \\
D4 & an EV user & 7 \\
\hline
\end{tabular}

Note: TGOOD is the abbreviation of Qingdao TGOOD Electric Co.,Ltd in China.

On the basis of $\bar{D}^{e}$ expressed in Equation (4), the values in Table 1 are transformed into the group direct-relation matrix $\widetilde{Z}$.

$$
\widetilde{Z}=\left[\begin{array}{ccccc}
(N O, 0) & (H, 0) & (L,-0.25) & (L,-0.25) & (V L, 0) \\
(V L, 0.25) & (N O, 0) & (L,-0.25) & (H,-0.5) & (V L, 0.25) \\
(L,-0.5) & (L, 0) & (N O, 0) & (L, 0) & (V L,-0.25) \\
(V L,-0.25) & (H,-025) & (V L, 0.25) & (N O, 0) & (V L,-0.25) \\
(V L,-0.25) & (V L, 0.25) & (L,-0.5) & (L,-0.25) & (N O, 0)
\end{array}\right]
$$


Table 3. The initial direct-relation matrices by decision makers. PL—political/legal risk; EM-economic/market risk; SE-social/environment risk; $\mathrm{PT}$-project/technical risk; MR—-managing risk; NO—no influence; VL—very low influence; L—low influence; $\mathrm{H}$-high influence; $\mathrm{VH}$-very high influence.

\begin{tabular}{|c|c|c|c|c|c|c|c|c|c|c|c|c|c|c|c|c|c|c|c|c|}
\hline Decision Maker & & & D1 & & & & & D2 & & & & & D3 & & & & & D4 & & \\
\hline Criteria & PL & EM & SE & PT & MR & PL & EM & SE & PT & MR & PL & EM & SE & PT & MR & PL & EM & SE & PT & MR \\
\hline PL & $\mathrm{NO}$ & $\mathrm{VH}$ & $\mathrm{L}$ & $\mathrm{H}$ & VL & $\mathrm{NO}$ & $\mathrm{H}$ & $\mathrm{L}$ & VL & $\mathrm{NO}$ & $\mathrm{NO}$ & $\mathrm{L}$ & VL & VL & VL & $\mathrm{NO}$ & $\mathrm{H}$ & $\mathrm{L}$ & $\mathrm{L}$ & $\mathrm{L}$ \\
\hline EM & VL & $\mathrm{NO}$ & VL & $\mathrm{H}$ & $\mathrm{H}$ & $\mathrm{L}$ & $\mathrm{NO}$ & $\mathrm{H}$ & $\mathrm{L}$ & $\mathrm{NO}$ & VL & $\mathrm{NO}$ & VL & $\mathrm{L}$ & VL & VL & NO & $\mathrm{L}$ & $\mathrm{H}$ & VL \\
\hline SE & $\mathrm{L}$ & $\mathrm{VH}$ & $\mathrm{NO}$ & $\mathrm{H}$ & $\mathrm{L}$ & VL & VL & $\mathrm{NO}$ & $\mathrm{NO}$ & VL & VL & VL & NO & $\mathrm{L}$ & NO & $\mathrm{L}$ & $\mathrm{L}$ & $\mathrm{NO}$ & $\mathrm{H}$ & $\mathrm{NO}$ \\
\hline PT & VL & $\mathrm{L}$ & VL & $\mathrm{NO}$ & VL & $\mathrm{NO}$ & $\mathrm{VH}$ & $\mathrm{L}$ & $\mathrm{NO}$ & $\mathrm{NO}$ & VL & VL & $\mathrm{NO}$ & $\mathrm{NO}$ & $\mathrm{NO}$ & VL & $\mathrm{VH}$ & $\mathrm{L}$ & $\mathrm{NO}$ & $\mathrm{L}$ \\
\hline MR & $\mathrm{L}$ & $\mathrm{L}$ & $\mathrm{L}$ & $\mathrm{L}$ & $\mathrm{NO}$ & VL & $\mathrm{NO}$ & $\mathrm{L}$ & $\mathrm{NO}$ & $\mathrm{NO}$ & NO & VL & VL & $\mathrm{L}$ & $\mathrm{NO}$ & VL & $\mathrm{L}$ & VL & $\mathrm{H}$ & $\mathrm{NO}$ \\
\hline
\end{tabular}


The normalized direct-relation matrix $X$ is computed based on Equation (7), as shown in Table 4 .

Table 4. Normalized direct-relation matrix X.

\begin{tabular}{cccccc}
\hline & PL & EM & SE & PT & MR \\
\hline PL & 0 & 0.400 & 0.233 & 0.233 & 0.133 \\
EM & 0.167 & 0.000 & 0.233 & 0.333 & 0.167 \\
SE & 0.200 & 0.267 & 0.000 & 0.267 & 0.100 \\
PT & 0.100 & 0.367 & 0.167 & 0.000 & 0.100 \\
MR & 0.100 & 0.167 & 0.200 & 0.233 & 0.000 \\
\hline
\end{tabular}

The indirect-relation matrix $\mathrm{H}$ is calculated by Equation (8), as shown in Table 5.

Table 5. Indirect-relation matrix $\mathrm{H}$.

\begin{tabular}{cccccc}
\hline & PL & EM & SE & PT & MR \\
\hline PL & 0.751 & 1.296 & 0.974 & 1.245 & 0.651 \\
EM & 0.641 & 1.252 & 0.860 & 1.068 & 0.566 \\
SE & 0.607 & 1.147 & 0.869 & 1.045 & 0.562 \\
PT & 0.569 & 0.979 & 0.756 & 0.992 & 0.505 \\
MR & 0.527 & 0.975 & 0.692 & 0.875 & 0.474 \\
\hline
\end{tabular}

Table 6 shows the total-relation matrix T based on Equation (9).

Table 6. Total-relation matrix T.

\begin{tabular}{cccccc}
\hline & PL & EM & SE & PT & MR \\
\hline PL & 0.751 & 1.696 & 1.207 & 1.478 & 0.784 \\
EM & 0.808 & 1.252 & 1.093 & 1.401 & 0.733 \\
SE & 0.807 & 1.414 & 0.869 & 1.312 & 0.662 \\
PT & 0.669 & 1.346 & 0.923 & 0.992 & 0.605 \\
MR & 0.627 & 1.142 & 0.892 & 1.108 & 0.474 \\
\hline
\end{tabular}

Influences among the criteria (prominence and relation) and their relative weights of risk factors in dimensions can be depicted from Equations (10) to (13), as shown in Table 7.

Table 7. Influences among the criteria and their relative weights of risk factors.

\begin{tabular}{cccccccc}
\hline & $\boldsymbol{r}$ & $\boldsymbol{c}$ & $\mathbf{P}$ & $\mathbf{R}$ & $\boldsymbol{w}_{j}$ & $\overline{\boldsymbol{w}_{j}}$ & Rank \\
\hline PL & 5.915 & 3.663 & 9.578 & 2.252 & 9.839 & 0.194 & 4 \\
EM & 5.287 & 6.850 & 12.137 & -1.563 & 12.237 & 0.242 & 1 \\
SE & 5.064 & 4.985 & 10.049 & 0.079 & 10.049 & 0.198 & 3 \\
PT & 4.536 & 6.291 & 10.827 & -1.755 & 10.968 & 0.216 & 2 \\
MR & 4.244 & 3.259 & 7.503 & 0.986 & 7.567 & 0.149 & 5 \\
\hline
\end{tabular}

Meanwhile, influences among risk factors and their relative weights in $\mathrm{C}$ level can be calculated, as shown in Table 8 (because of space limitations, only calculation results are given here).

The results show that the factor of government intervention (C3) is the most important risk criterion $\left(\overline{w_{j}}=0.065\right)$ in the PL risk dimension, while the criterion of delay in project approvals and permits $(\mathrm{C} 2)$ is the least important factor $\left(\overline{w_{j}}=0.042\right)$. EVCI-PPP projects have obvious geographical features. The local government may impose clauses on the contract to increase regional economic returns, for example, hiring local employees and using local building materials, which hinder the normal operation of PPP projects. 
Table 8. Influences among risk factors and their relative weights in C level.

\begin{tabular}{cccccccc}
\hline & $\boldsymbol{r}$ & $\boldsymbol{c}$ & $\mathbf{P}$ & $\mathbf{R}$ & $\boldsymbol{w}_{j}$ & $\overline{\boldsymbol{w}_{j}}$ & Rank \\
\hline C1 & 2.648 & 0.926 & 3.574 & 1.722 & 15.739 & 0.051 & 8 \\
C2 & 1.856 & 1.704 & 3.560 & 0.152 & 12.697 & 0.041 & 13 \\
C3 & 2.731 & 1.645 & 4.376 & 1.086 & 20.329 & 0.065 & 4 \\
C4 & 2.016 & 1.027 & 3.043 & 0.989 & 10.238 & 0.033 & 16 \\
C5 & 1.804 & 2.317 & 4.121 & -0.513 & 17.246 & 0.056 & 5 \\
C6 & 1.278 & 0.657 & 1.935 & 0.621 & 4.130 & 0.013 & 22 \\
C7 & 1.545 & 2.316 & 3.861 & -0.771 & 15.502 & 0.050 & 9 \\
C8 & 1.317 & 4.074 & 5.391 & -2.757 & 36.664 & 0.118 & 1 \\
C9 & 2.051 & 1.583 & 3.634 & 0.468 & 13.425 & 0.043 & 12 \\
C10 & 1.221 & 2.012 & 3.233 & -0.791 & 11.078 & 0.036 & 15 \\
C11 & 1.982 & 1.675 & 3.657 & 0.307 & 13.468 & 0.043 & 11 \\
C12 & 1.693 & 1.726 & 3.419 & -0.033 & 11.691 & 0.038 & 14 \\
C13 & 1.403 & 0.853 & 2.256 & 0.550 & 5.392 & 0.017 & 21 \\
C14 & 2.024 & 1.952 & 3.976 & 0.072 & 15.814 & 0.051 & 7 \\
C15 & 2.47 & 1.429 & 3.899 & 1.041 & 16.286 & 0.052 & 6 \\
C16 & 1.466 & 3.109 & 4.575 & -1.643 & 23.630 & 0.076 & 2 \\
C17 & 1.331 & 2.947 & 4.278 & -1.616 & 20.913 & 0.067 & 3 \\
C18 & 1.435 & 2.347 & 3.782 & -0.912 & 15.135 & 0.049 & 10 \\
C19 & 1.817 & 1.255 & 3.072 & 0.562 & 9.753 & 0.031 & 17 \\
C20 & 1.688 & 1.158 & 2.846 & 0.530 & 8.381 & 0.027 & 18 \\
C21 & 1.342 & 1.077 & 2.419 & 0.265 & 5.922 & 0.019 & 20 \\
C22 & 1.642 & 0.971 & 2.613 & 0.671 & 7.278 & 0.023 & 19 \\
\hline
\end{tabular}

Revenue risk (C8), with an influence weight of 0.069 , is the most important risk factor in the EM risk dimension. Following this, financial risk $(\mathrm{C} 5)\left(\overline{w_{j}}=0.056\right)$ and payment risk $(\mathrm{C} 7)\left(\overline{w_{j}}=0.050\right)$ are the second and third risk factors, respectively. For private investors, achieving acceptable revenue is the main purpose and revenue of projects is influenced by various risk elements.

Among the SE risk criteria, public opposition (C11) is the most significant criterion, with $\overline{w_{j}}=$ 0.043. The land acquisition (C12) and environmental risk (C13) are the second and third important factors in SE dimension, respectively. To ensure the charging revenue, public charging facilities are installed in dense business districts. However, urban land is tight, and the large-scale construction of charging facilities is inseparable from government support.

Completion risk (C16) and construction/operation cost overrun (C17) are the two significant elements with weights of 0.076 and 0.067 , respectively, under the PT risk dimension. Multiple factors may delay the project and cause completion risk, such as inadequate PPP experience, weather risk, force majeure, and so on.

Likewise, in the MR dimension, misallocation of rights and responsibilities (C20) $\left(\overline{w_{j}}=0.027\right)$ is viewed as the most critical criterion, compared with others such as lack of communication (C22) and poor fund supervision (C21). Risk and uncertainty are associated with any phase in the life of a PPP project, and significantly influence a project's outcomes. Consequently, risk allocation is a determinant of PPP projects. Inappropriate allocation of risks leads to inefficiency of management and high costs, and reduces the participation of private sectors in EVCI-PPP projects.

As shown in Table 8, the results illustrate the superficial dependence existing among 5 dimensions and 22 criteria. Furthermore, a cause-effect diagram is constructed with the vertical axis R named "Relation" and the horizontal axis P named "Prominence", as showed in Figure 4. Through the values of $R$, risk criteria are divided into two groups: the cause group $(R>0$, over the horizontal axis $P)$ and effect group $(R<0$, under the horizontal axis $\mathrm{P})$. Moreover, the values of $\mathrm{P}$ present how important the factor is. The importance of risk factors is ranked as follows: $\mathrm{C} 8>\mathrm{C} 16>\mathrm{C} 17>\mathrm{C} 3>\mathrm{C} 5>\mathrm{C} 15>\mathrm{C} 14>$ $\mathrm{C} 1>\mathrm{C} 7>\mathrm{C} 18>\mathrm{C} 11>\mathrm{C} 9>\mathrm{C} 2>\mathrm{C} 12>\mathrm{C} 10>\mathrm{C} 4>\mathrm{C} 19>\mathrm{C} 20>\mathrm{C} 22>\mathrm{C} 21>\mathrm{C} 13>\mathrm{C} 6$. As illustrated in Figure 4, the causal factors are C10, C3, C9, C4, C15, C1, C19, C22, C14, C20, C21, C22, C6, and C13, and are ranked as follows: $\mathrm{C} 1>\mathrm{C} 3>\mathrm{C} 15>\mathrm{C} 4>\mathrm{C} 22>\mathrm{C} 6>\mathrm{C} 19>\mathrm{C} 13>\mathrm{C} 20>\mathrm{C} 9>\mathrm{C} 11>\mathrm{C} 21>\mathrm{C} 2>$ 
C14. The following risk factors are attributed to the effect group, and are ranked as $\mathrm{C} 12>\mathrm{C} 5>\mathrm{C} 7>$ $\mathrm{C} 10>\mathrm{C} 18>\mathrm{C} 17>\mathrm{C} 16>\mathrm{C} 8$.

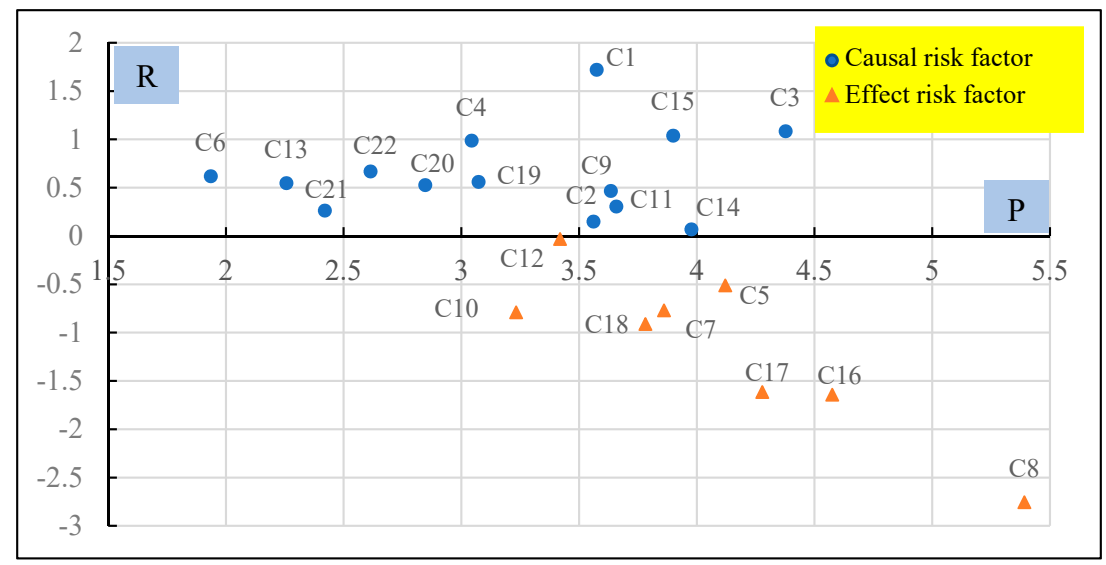

Figure 4. The cause-effect diagram of risk factors in EVCI-PPPs. Note: the criteria with values of $\mathrm{R}>0$ are in the causal group, whereas those with $\mathrm{R}<0$ are in the effect group. $\mathrm{R}$-relation; $\mathrm{P}$-prominence.

On the basis of Figure 4, C1 has the highest $\mathrm{R}$ score among all risk criteria, which demonstrates that $\mathrm{C} 1$ is the primary causal factor. Thus, to avoid the chain reaction, relevant policy and law should be adopted to advance the sustainable development of EVCI-PPP projects. Meanwhile, C8 is the most important factor with the highest $\mathrm{P}$ value, which means that $\mathrm{C} 8$ is in a vital stage in the success of EVCI-PPP projects in China.

\section{Discussion}

On the basis of Figure 5a, EM and PT risk have more influence on the other three risk dimensions. This demonstrates that decision makers should consider EM and PT risk dimensions first when operating EVCI-PPP projects. The revenue of charging infrastructure projects is affected by the fluctuating market, especially in the open market. The purpose of social capital investment in charging facility projects is to realize profits. Therefore, the economic/market risk dimension is the most important criterion for EVCI-PPP projects, which should be given priority by project managers.

From Figure $5 \mathrm{~b}$ in the PL risk dimension, it can be found that $\mathrm{C} 1, \mathrm{C} 2, \mathrm{C} 3$, and $\mathrm{C} 4$ are causal factors and can be sorted as $\mathrm{C} 1>\mathrm{C} 3>\mathrm{C} 4>\mathrm{C} 2$, according to R score. Meanwhile, $\mathrm{C} 3$ is the most significant factor in this dimension, which means that the government should not over-interfere with the design, financing, construction, and operation to ensure the normal operation of PPP projects. The risk factor $\mathrm{C} 2$ is influenced by other three risk criteria. This means that two parties, especially the government, should take some measures to increase the efficiency of approvals and permits.

As shown in Figure 5c, C6 and C9 are classed into the causal group in the EM risk dimension. The insufficient market share of EVs has a large $p$ value, which shows that $C 9$ is a more significant risk factor in this dimension. A sufficient market share of EVs is the basic guarantee for the operation of charging facilities. The risk factors of $\mathrm{C} 5, \mathrm{C} 7, \mathrm{C} 8$, and $\mathrm{C} 10$ are indicated as influenced risks and can be ranked as $\mathrm{C} 5>\mathrm{C} 7>\mathrm{C} 10>\mathrm{C} 8$ by $\mathrm{R}$ values. Meanwhile, $\mathrm{C} 8$ is the most important risk criterion in this dimension. As for influence relations, $\mathrm{C} 5, \mathrm{C} 6, \mathrm{C} 7, \mathrm{C} 9$, and $\mathrm{C} 10$ influence $\mathrm{C} 8$. This indicates that the revenue risk plays an important role in EVCI-PPP projects.

As illustrated in Figure 5d, C11 and C13 are classified into the causal group and C12 is the effect element. They are scored as $\mathrm{C} 13>\mathrm{C} 11>\mathrm{C} 12$. With the respect to the influence relations, $\mathrm{C} 13$ has a large effect on C11 and C12, and C11 influences C12. The environment risk and public opposition will increase the difficulty of land acquisition.

On the basis of Figure 5e, it can be found that in the PT risk dimension, C14, C15, and C19 are causal factors, while C16, C17, and C18 are effect factors. They are ranked as C15 > C14 > C19>C18> 
C17 > C16, according to R scores. C15 and C19 have a significant effect on other risk criteria, which demonstrates that PPP project experience is essential in order to have the concession to construct and operate EVCI-PPP projects. Additionally, updated charging technology brings certain difficulties to the construction and operation. Operators need to put effort and funds into updating equipment and training employees, which may have a negative effect on cost overrun and completion. Furthermore, $\mathrm{C} 16$ is the most significant criterion in this risk group. This indicates that taking target measures to control the completion is beneficial to the success of PPP projects.

On the basis of Figure $5 f$, the ranking of MR criteria is C22 > C20 > C21, according to R scores, and C20, C21, and C22 are all in the cause group. With respect to the influence relation, C22 has influences on C20 and C21, and C20 influences C21. In practical situations, the PPP mode emphasizes the partnership between the government and concessionaire, thus sound communication between two parties is important for the success of EVCI-PPP projects. The private partners are responsible for financing, construction, and operation. Correspondingly, they should burden the risks of financing risk, completion risk, and cost overrun risk. Furthermore, the government should assist them in access to land use rights, auditing the items, and planning permits to guarantee that the private sector constructs PPP projects legally. The appropriate allocation of rights and responsibilities helps give play to their respective advantages of the government and private sectors, which achieves a win-win situation.

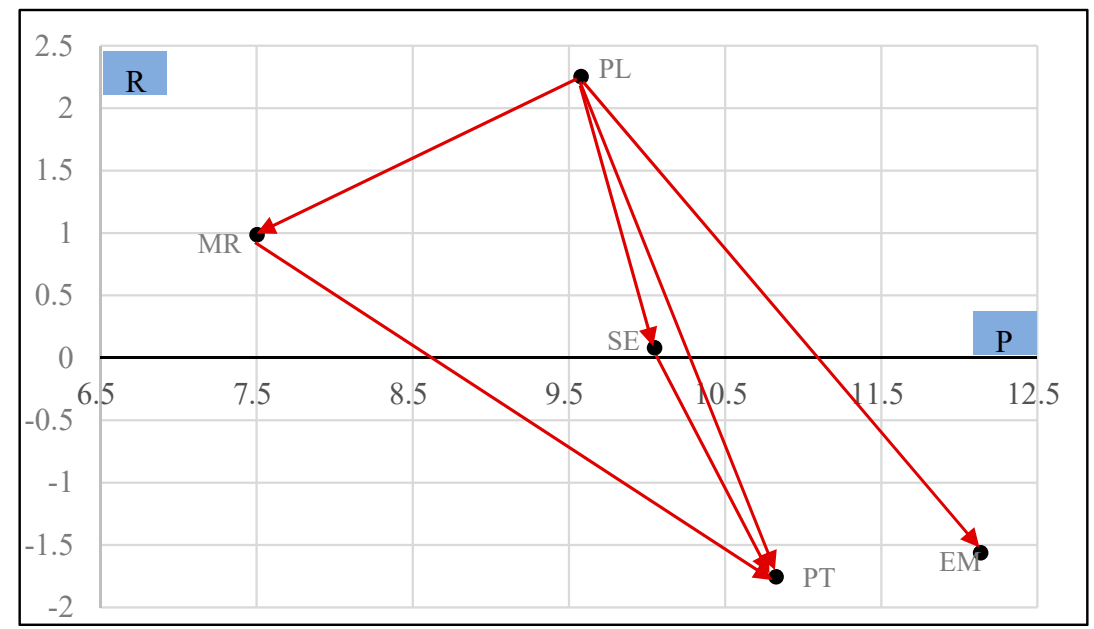

(a) Among the five dimensions.

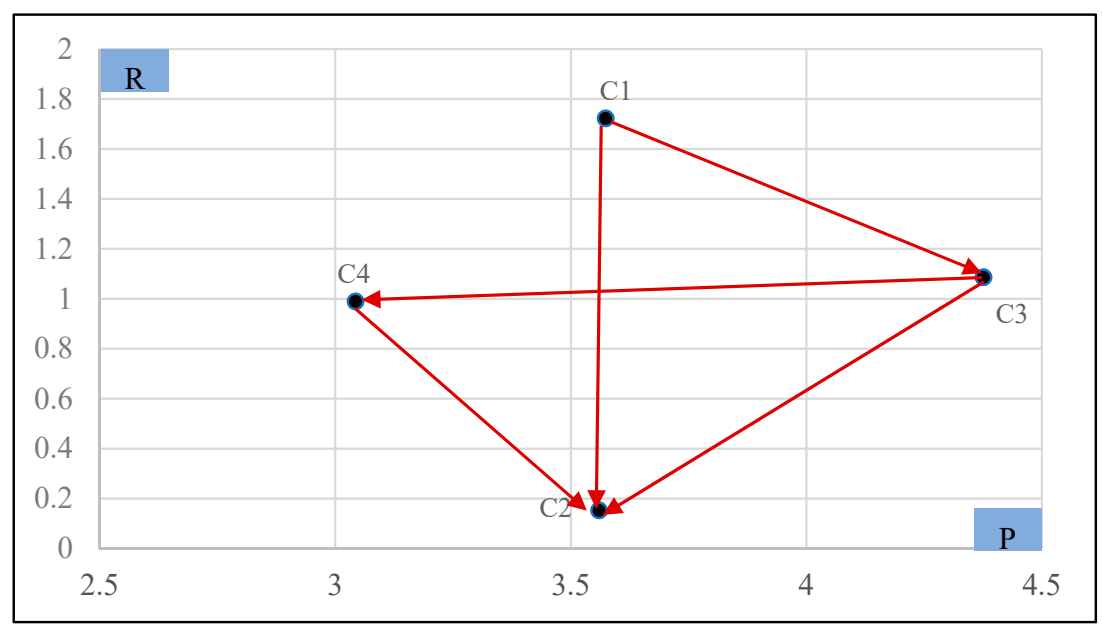

(b) The cause-effect diagram of political/legal risk factors.

Figure 5. Cont. 


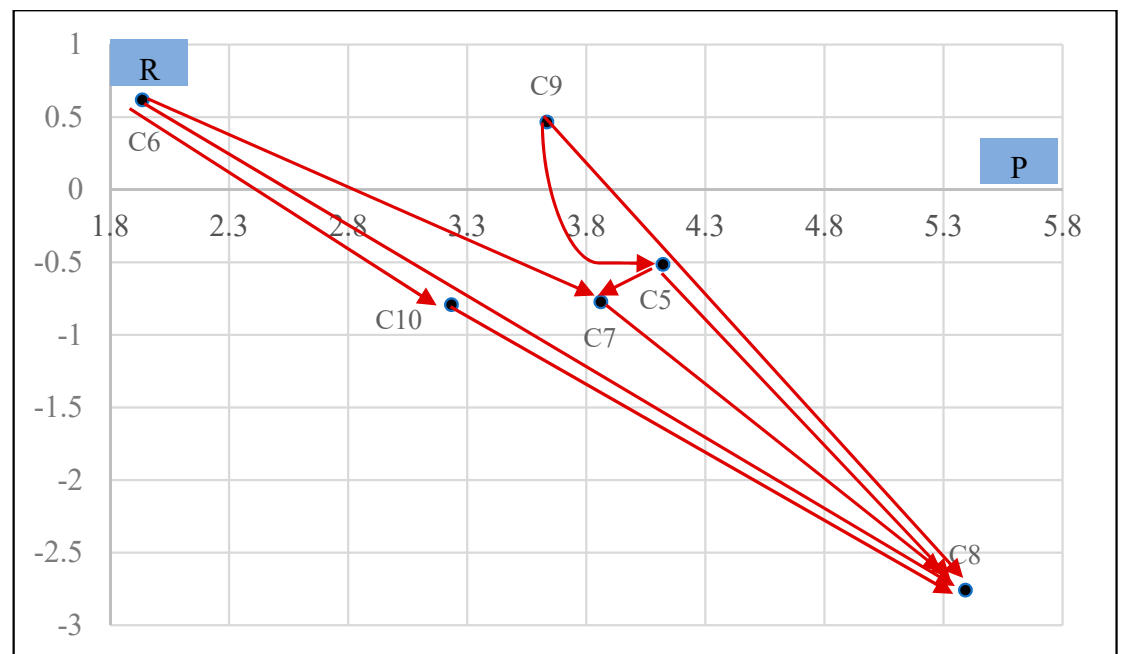

(c) The cause-effect diagram of economic/market risk factors.

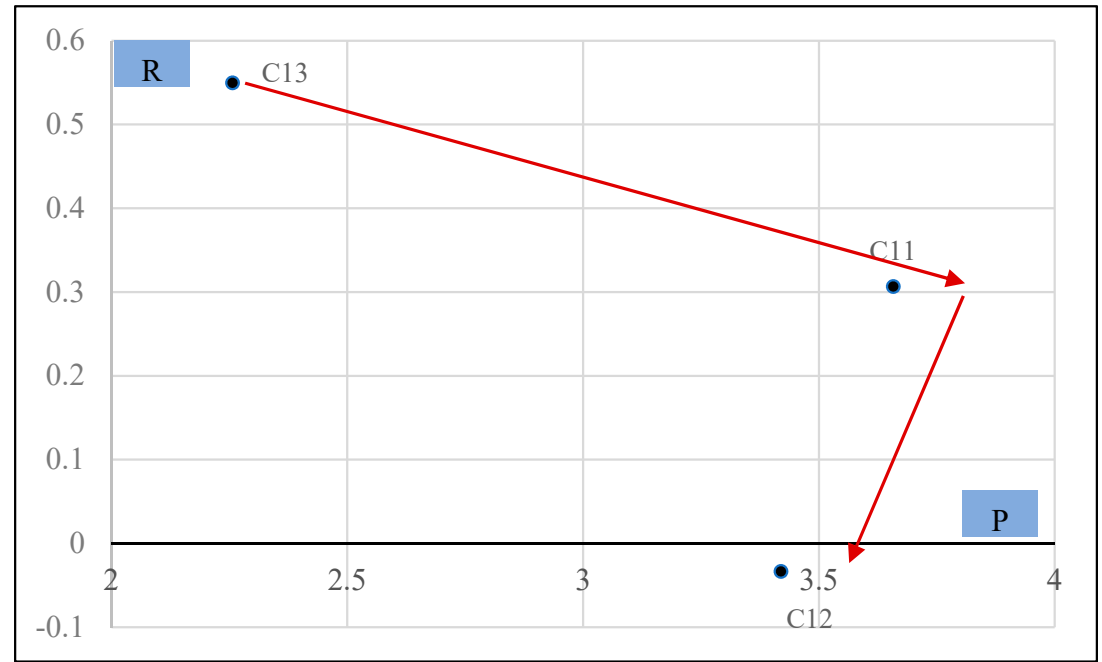

(d) The cause-effect diagram of social/environmental risk factors.

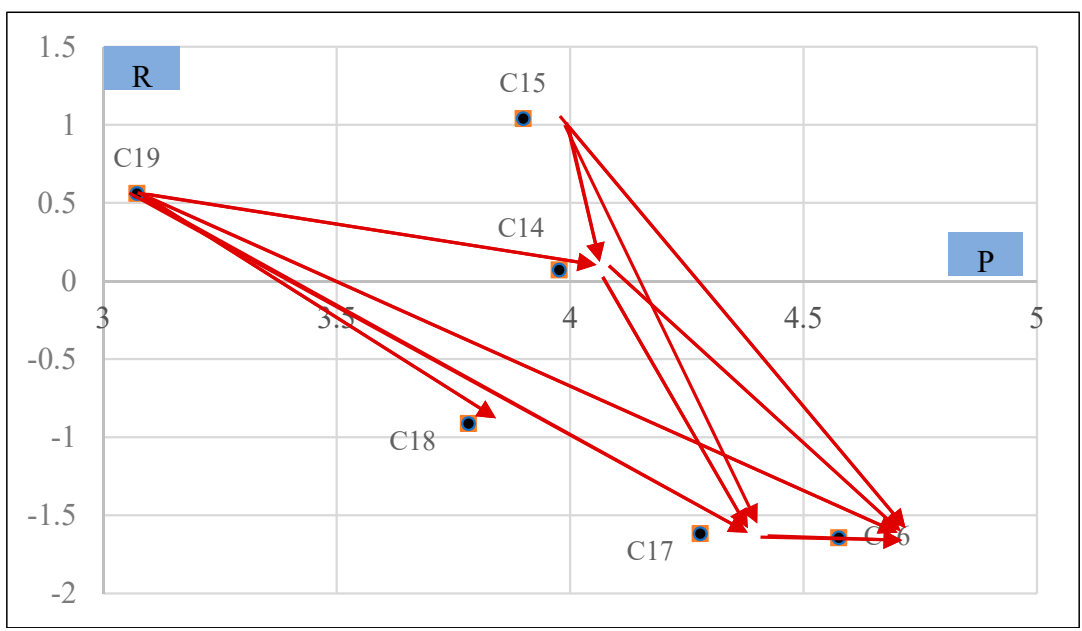

(e) The cause-effect diagram of project/technical risk factors.

Figure 5. Cont. 


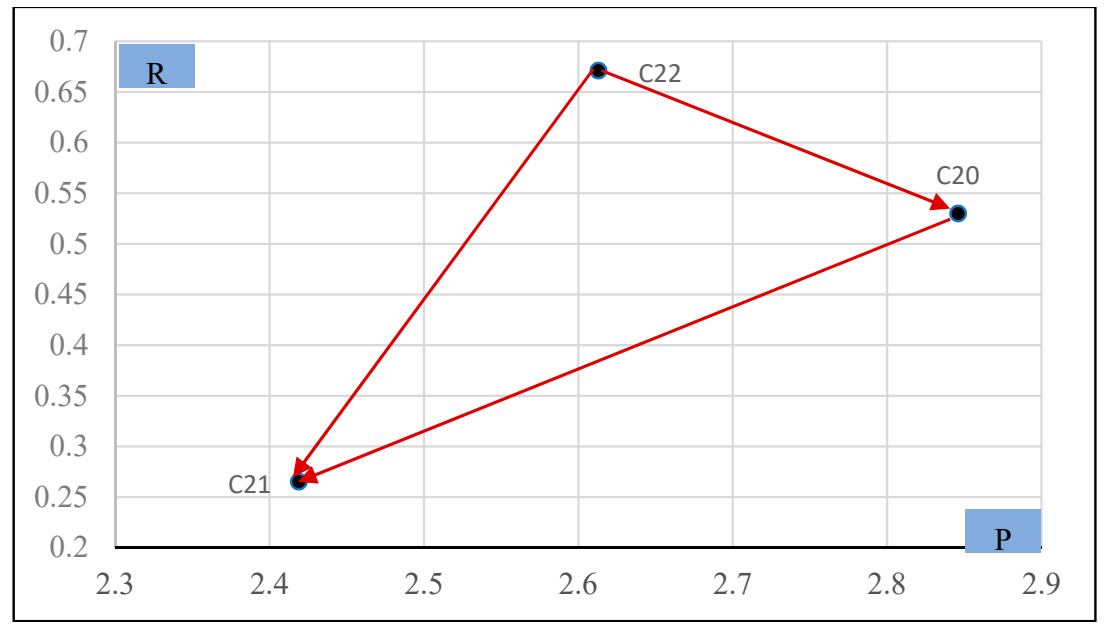

(f) The cause-effect diagram of managing risk factors.

Figure 5. The cause-effect diagram of the dimensions (a) and criteria of (b) pollical/legal risk, (c) economic/market risk, (d) social/environmental risk, (e) project/technical risk, and (f) managing risk.

\subsection{Cause Group}

As shown in Figure 4, 14 criteria are classified into the cause group with positive R scores. Among the factors of the causal group, $\mathrm{C} 1$ has the highest value of $\mathrm{R}$, which indicates that it has more effect on EVCI-PPP projects than it receives from other criteria. Additionally, the degree of influential impact (2.648) of $\mathrm{C} 1$ has the second largest value among the factors, demonstrating that $\mathrm{C} 1$ has a great influence on other risk factors. In China, charging infrastructure is in nurturing stage, and is affected by many uncertain factors, especially from the EV industry policies, region regulations, PPP laws, and so on. Changes in any chain will affect the success of EVCI-PPP projects. The risk factor C3, with the highest $p$ score, has the second highest value of $\mathrm{R}$, and its influential impact degree (2.731) is the highest among all the factors, which demonstrates that government intervention has a great effect on the operation of projects. Both the $\mathrm{r}_{i}$ and $\mathrm{c}_{i}$ values of $\mathrm{C} 15$ are relatively higher, and it has a high $p$ value (3.899) and the third highest value of $R$, which implies that PPP project experience should be paid more attention when choosing concessionaire. C6 has the lowest $p$ value in this group and both the $r_{i}$ and $c_{i}$ values are not high enough, which means that C6 lacks great importance in this system, and it is unnecessary to take $\mathrm{C} 6$ into consideration.

\subsection{Effect Group}

The criteria belonging to the effect group tend to be influenced by others. The risk criteria, namely, $\mathrm{C} 5, \mathrm{C} 7, \mathrm{C} 8, \mathrm{C} 10, \mathrm{C} 12, \mathrm{C} 16, \mathrm{C} 17$, and C18, are divided into the effect group. The factor $\mathrm{C} 8$ has a high $p$ value (5.391), which ranks first among all the elements, indicating that $C 8$ is very significant in EVCI-PPP projects. In addition, C8 has the lowest value of $\mathrm{R}$, meaning that it is easily affected by other risk criteria. The R-value of the factor $\mathrm{C} 12$ is slightly below 0 , suggesting that it is just slightly net affected by other factors. The significant degree $\mathrm{P}$ of $\mathrm{C} 12$ is 3.419 , which is not high enough to take target measures to control it. The effect factors, C16, C17, and C18, have the same common features. Although they have high $p$ values, their degree of influential impact is not high enough, which indicates that they can be easily avoided by adjusting other factors.

\section{Suggestions}

The risk categories are classified into five aspects: political/legal risk (PL), economic/market risk (EM), social/environment risk (SE), project/technical risk (PT), and managing risk (MR). The criteria weights are $18.99 \%, 31.56 \%, 9.83 \%, 32.68 \%$, and $6.95 \%$, respectively, as shown in Figure 6 . The risk categories of PT and EM are significant to EVCI-PPP projects, to which close attention should be paid. 
In the sub-criteria, the criterion C8 has the highest weight among the 22 criteria (see Figure 7), and the top 10 criteria affecting EVCI-PPP projects are determined-namely, revenue risk, poor completion risk, construction/operation cost overrun, government intervention, financial risk, inadequate PPP project experience, poor construct design, change in policy and low, payment risk, and unsatisfactory charging service. Among these top 10 risk factors, there are 4 causal criteria (above the horizontal axis) and 6 effect criteria (below the horizontal axis), as presented in Figure 8.

On the basis of the calculation results, this section provides some suggestions from five aspects to mitigate the risks of projects.

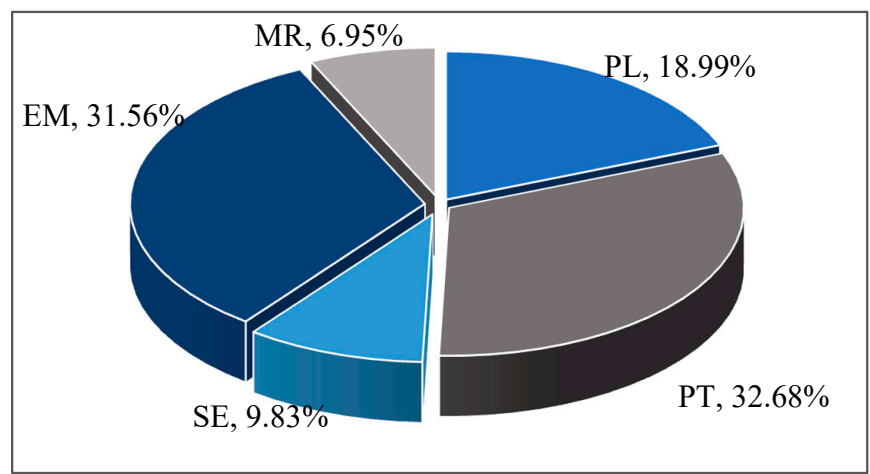

Figure 6. Critical risk categories and criteria weights.

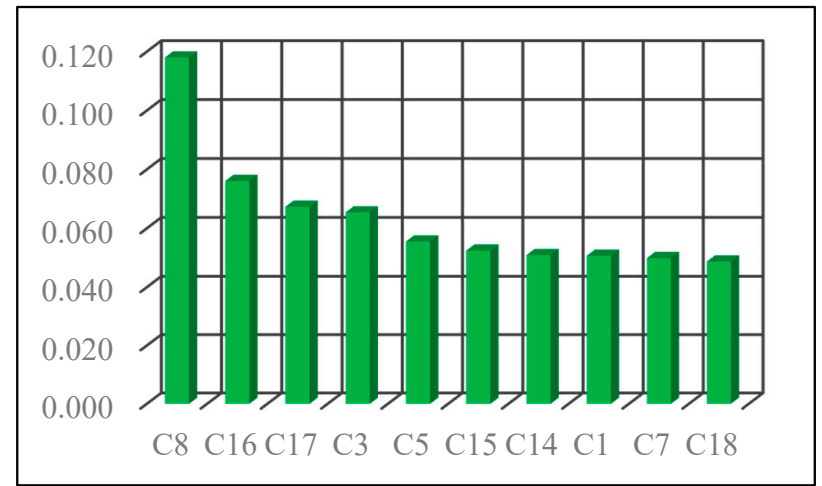

Figure 7. Top 10 criteria of risk factors.

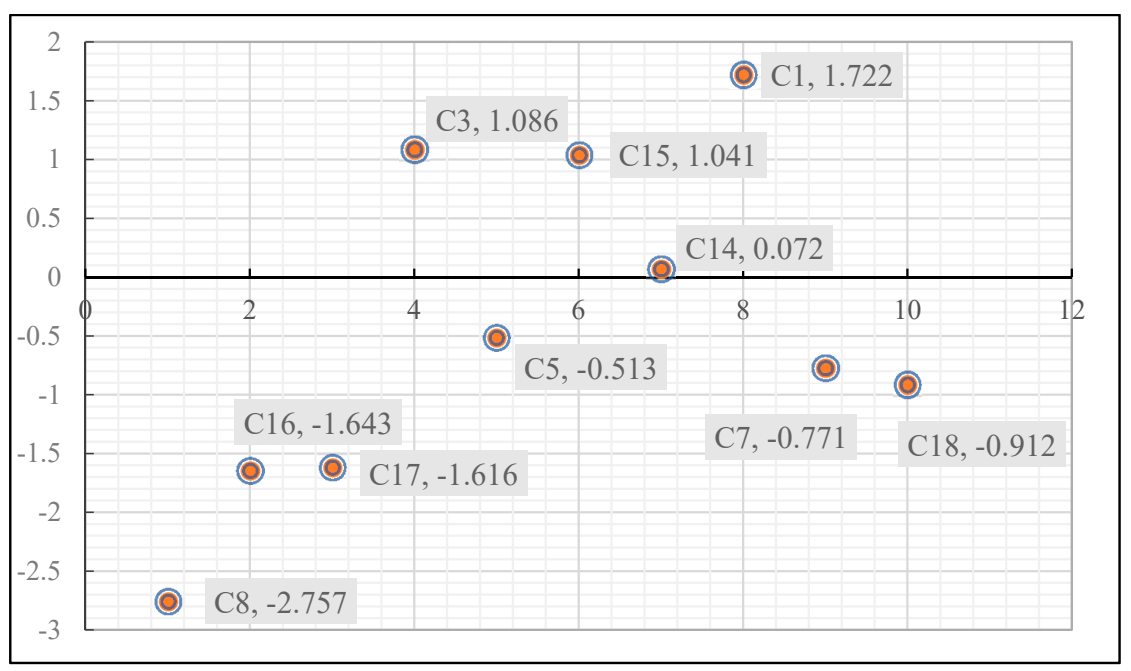

Figure 8. $\mathrm{R}$ values of the top 10 risk criteria. 


\subsection{Political/Legal Aspect}

A sound political framework is fundamental to the success of the PPP model in becoming popular in EVCI projects. Currently, the development of EVs and charging facilities benefit from adventurous policies. Although current political attitude is the incentive, changes in incentive policies in the future may bring indefinite effects on PPP projects, because EVCI-PPP projects have a long-term period and are influenced by the political policies of the EV industry and PPP regulations. For this concern, the government should promote policy changes step by step. Meanwhile, the private operators should focus on the changes of industry policies and establish a close corporation with relevant departments to ensure support for approvals and permits. Besides, to enable charging operators to give the superiority of management, the government should reduce unreasonable interventions, simplify the approval process, and improve work efficiency. The competent government departments should establish the green channel for regulating the approval, simplifying the permits, and optimizing the procedures. Furthermore, increasing the transparency of bidding can effectively avoid government corruption and reduce project risks.

\subsection{Economic/Market Aspect}

Economic risks come from the market-high inflation rates, financial risk, payment, and revenue, and so on. The market of financial and charging demand is changeable and cannot be identified precisely, which demonstrates that economic/market risk is uncontrollable. Charging revenue depends on government subsidy, charging volume, and charging fee. In order to guarantee the private sectors' revenues, the "take or pay" clause is a universal measure in EVCI-PPP projects [20]. On the basis of our investigations, the concession contract not only sets government acquisitions terms and the minimum attractive rate return, but also regulates the maximum charging price to avoid super-profit. Charging volume is influenced by EVs' market share. Thus, multiple measures should be taken to popularize the usage of EVs, for example, increasing the investment of R\&D (research and development) of EVs, reducing the comprehensive cost of EVs, and improving the coverage of EVs. Concerning completion risk, although PPP projects are characterized by monopoly, various charging supply methods, battery changing, private charging piles, and so on damage the uniqueness of EVCI-PPP projects. Operators must conduct a market survey, select outstanding charging station sites, and optimize infrastructure layout to improve the competitiveness of EVCI-PPP projects and reduce the completion risk. Furthermore, to minimize payment risk, the payment of process, time, and amount of charging subsidy should be stipulated in the concession agreement. The government and private partners should work together to avoid EM risks.

\subsection{Social/Environment Aspect}

Social/environment risks arise from three aspects; namely, public opposition, land acquisition, and environmental risk. Public opposition and environmental risk can increase the risk of land acquisition. It is required that private sectors should adopt environmentally-friendly materials and apply advanced technologies to reduce environmental pollution. Furthermore, the government must reserve special land resources for charging infrastructure and assist social capital to obtain construction land legally. Only cooperation of the government and private sectors can reduce the occurrence of social/environment risk.

\subsection{Project/Technical Aspect}

To avoid the risks of projects, the government should establish a reasonable evaluation index system, and implement a competitive mechanism to choose appropriate social capitals. The partners would do better to have experience in PPP projects; perform well in financing, construction, and design; and, finally, provide sound charging services to solve the current problem of charging mileage. Additionally, the operators should optimize the construction layout at various stages, especially in 
the construction and operation phase, controlling the construction cost and period strictly. On the technical level, because the charging operators are in a weak position in the overall EV industrial chain, and the participation of car companies is relatively low, the upgrade of power charging battery technology is difficult to coordinate. At the same time, although the total amount of charging facilities is large, the technical level is low, and various charging facilities can only achieve one-way charging, which means it is difficult to interact with the grid in terms of charging technology and makes it difficult to achieve charging interaction of the power grid. To overcome the above issues, the government could select excellent car companies for the shortlist when choosing partners. Furthermore, the operators also need to pay more attention to the technology limitations and use advanced technology to provide intelligent charging services.

\subsection{Managing Aspect}

Communication is the basis for cooperation between two parties, the government and concessionaire. Strengthening the exchange of information can promptly reveal problems in cooperation and measures can be taken to prevent them from aggravating. In the early stage of projects, the government and private sectors should make detailed regulations on risks, benefits, rights, and obligations to avoid dereliction and blaming. The government should supervise finances to prevent social capital from abusing public funds and defrauding subsidies. Although the government's role is irreplaceable in PPP projects, the private investors should bear some obligations, such as providing quality charging service, a low charging price, and so on. Only through effective coordination between the government and concessionaire can the success of EVCI-PPP projects be ensured [15].

\section{Conclusions}

Risk identification and analysis is critical to ensuring the success of EVCI-PPP projects, as risks are present throughout the whole life of the projects. The interrelationships among criteria are always neglected in the existing research. This paper developed a risk identification and analysis model based on 2-tuple and the DEMATEL technique to investigate internal relations among risk factors of EVCI-PPP projects, which can be applied by the government and concessionaire to allocate resources and control risks. The results show that the two dimensions of economic/market risk and project/technical risk are critical to EVCI-PPP projects. On the basis of the cause-effect relationships, revenue risk ( $\mathrm{C} 8)$ is the most affected risk factor, and change in policy and law (C1) is a significant causal factor. Thus, the government and decision makers should focus on $\mathrm{C} 8$ and $\mathrm{C} 1$ when popularizing the PPP model in charging infrastructure projects. In the whole life cycle, the projected revenue is not only related to the operation itself, but also to the related industry policies and market volume of electric vehicles. Incentive policies, such as subsidies and reserved land, have an important influence on the sustainable development of EVCI-PPP projects. Thus, the government should establish a sound political framework for EVCI-PPP projects.

The interrelationships among different risk factors that have an influence on the identification of the importance and controlling risk factors are investigated. This consideration involves the domino effect among risk criteria in the process of risk identification and analysis, which is in accordance with real situations. Therefore, it is beneficial to the government and social capital to carry out risk management in EVCI-PPP projects.

This paper also has some limitations. Because of inadequate project experience in EVCI-PPP projects in China, risk identification has inevitable shortcomings. The risk factor set will be upgraded as the popularization of EVCI-PPP projects advances. Then, although 2-tuple fuzzy linguistic theory has the advantage of being able to deal with the evaluation issue in a linguistic environment, it does not work when the information is vague and incomplete. In terms of future research, a comprehensive risk evaluation system and new methods, such as interval and linguistic terms, will be considered.

Author Contributions: L.Z. provided professional guidance; Z.Z. designed the proposed model and wrote this paper; J.C. performed the experiments; and Z.K. investigated PPP projects. 
Funding: This work is funded by the 2017 Special Project of Cultivation and Development of Innovation Base (No. Z171100002217024).

Acknowledgments: The completion of this paper has been helped by many teachers and classmates. We would like to express our gratitude to them for their help and guidance.

Conflicts of Interest: The authors declare no conflict of interest.

\section{Nomenclature}

\begin{tabular}{|c|c|}
\hline \multicolumn{2}{|l|}{ Acronyms } \\
\hline DEMATAL & decision making trial and evaluation laboratory \\
\hline EV & electric vehicle \\
\hline EVCI & electric vehicle charging infrastructure \\
\hline GHG & greenhouse gas \\
\hline PPP & public private partnership \\
\hline PL & political/legal risk \\
\hline EM & economic/market risk \\
\hline SE & social/environment risk \\
\hline PT & project/technical risk \\
\hline MR & managing risk \\
\hline \multicolumn{2}{|l|}{ Sets } \\
\hline $\mathrm{C}$ & a set of risk factors \\
\hline$S$ & a set of linguistic term \\
\hline $\mathrm{E}$ & a set of experts' decision \\
\hline \multicolumn{2}{|l|}{ Matrix } \\
\hline $\mathrm{H}$ & the indirect relation matrix \\
\hline I & the identity matrix \\
\hline $\mathrm{T}$ & the overall relation matrix \\
\hline$x$ & the normalized direct-relation matrix \\
\hline Z & the initial direct-relation matrix \\
\hline$\hat{z}_{i j}$ & the group direct influence matrix \\
\hline \multicolumn{2}{|l|}{ Parameters } \\
\hline$\alpha_{i}$ & the numerical value of the symbolic translation \\
\hline$\beta$ & the symbolic linguistic aggregation value \\
\hline$c$ & the degree of being influenced \\
\hline$r$ & the influence degree \\
\hline $\bar{D}^{e}$ & the 2-tuple arithmetic mean operator \\
\hline$\hat{D}^{e}$ & the 2-tuple weighted average operator \\
\hline $\mathrm{P}$ & the prominence of risk criteria \\
\hline $\mathrm{R}$ & the relation of risk criteria \\
\hline$w_{j}$ & the relative importance of criterion $c_{j}$ \\
\hline$\overline{w_{j}}$ & the final weight of criterion $c_{j}$ \\
\hline
\end{tabular}

\section{References}

1. Yu, J.; Yang, P.; Zhang, K.; Wang, F.; Miao, L. Evaluating the Effect of Policies and the Development of Charging Infrastructure on Electric Vehicle Diffusion in China. Sustainability 2018, 10, 3394. [CrossRef]

2. Helmus, J.; van den Hoed, R. Key Performance Indicators of Charging infrastructure. World Electr. Veh. J. 2016, 8, 733. [CrossRef]

3. Yang, T.; Long, R.; Li, W. Suggestion on tax policy for promoting the PPP projects of charging infrastructure in China. J. Clean. Prod. 2018, 174, 133-138. [CrossRef]

4. Tan, Q.; Wang, M.; Deng, Y.; Yang, H.; Rao, R.; Zhang, X. The Cultivation of Electric Vehicles Market in China: Dilemma and Solution. Sustainability 2014, 6, 5493-5511. [CrossRef] 
5. Zhang, L.; Zhao, Z.; Xin, H.; Chai, J.; Wang, G. Charge pricing model for electric vehicle charging infrastructure public-private partnership projects in China: A system dynamics analysis. J. Clean. Prod. 2018, 199, 321-333. [CrossRef]

6. Yang, T.; Long, R.; Li, W.; Rehman, S. Innovative Application of the Public-Private Partnership Model to the Electric Vehicle Charging Infrastructure in China. Sustainability 2016, 8, 738. [CrossRef]

7. Carbonara, N.; Costantino, N.; Pellegrino, R. Concession period for PPPs: A win-win model for a fair risk sharing. Int. J. Proj. Manag. 2014, 32, 1223-1232. [CrossRef]

8. Xu, M.; Meng, Q.; Liu, K.; Yamamoto, T. Joint charging mode and location choice model for battery electric vehicle users. Transp. Res. Part B Methodol. 2017, 103, 68-86. [CrossRef]

9. Akbari, M.; Brenna, M.; Longo, M. Optimal Locating of Electric Vehicle Charging Stations by Application of Genetic Algorithm. Sustainability 2018, 10, 1076. [CrossRef]

10. Zhu, L.; Zhang, Q.; Lu, H.; Li, H.; Li, Y.; McLellan, B.; Pan, X. Study on crowdfunding's promoting effect on the expansion of electric vehicle charging piles based on game theory analysis. Appl. Energy 2017, 196, 238-248. [CrossRef]

11. Krause, J.; Ladwig, S.; Saupp, L.; Horn, D.; Schmidt, A.; Schwalm, M. Perceived Usage Potential of Fast-Charging Locations. World Electr. Veh. J. 2018, 9, 14. [CrossRef]

12. Zhang, X.; Liang, Y.; Liu, W. Pricing model for the charging of electric vehicles based on system dynamics in Beijing. Energy 2017, 119, 218-234. [CrossRef]

13. Palevičius, V.; Podviezko, A.; Sivilevičius, H.; Prentkovskis, O. Decision-Aiding Evaluation of Public Infrastructure for Electric Vehicles in Cities and Resorts of Lithuania. Sustainability 2018, 10, 904. [CrossRef]

14. Wu, T.; Zeng, B.; He, Y.; Tian, X.; Ou, X. Sustainable Governance for the Opened Electric Vehicle Charging and Upgraded Facilities Market. Sustainability 2017, 9, 2126. [CrossRef]

15. Liu, J.; Wei, Q. Risk evaluation of electric vehicle charging infrastructure public-private partnership projects in China using fuzzy TOPSIS. J. Clean. Prod. 2018, 189, 211-222. [CrossRef]

16. Wu, Y.; Song, Z.; Li, L.; Xu, R. Risk management of public-private partnership charging infrastructure projects in China based on a three-dimension framework. Energy 2018, 165, 1089-1101. [CrossRef]

17. Li, Y.; Zhan, C.; de Jong, M.; Lukszo, Z. Business innovation and government regulation for the promotion of electric vehicle use: Lessons from Shenzhen, China. J. Clean. Prod. 2016, 134, 371-383. [CrossRef]

18. Wu, Y.; Xu, C.; Li, L.; Wang, Y.; Chen, K.; Xu, R. A risk assessment framework of PPP waste-to-energy incineration projects in China under 2-dimension linguistic environment. J. Clean. Prod. 2018, 183, 602-617. [CrossRef]

19. Ke, Y.; Wang, S.; Chan, A.P.C.; Lam, P.T.I. Preferred risk allocation in China's public-private partnership (PPP) projects. Int. J. Proj. Manag. 2010, 28, 482-492. [CrossRef]

20. Xu, Y.; Chan, A.P.C.; Xia, B.; Qian, Q.K.; Liu, Y.; Peng, Y. Critical risk factors affecting the implementation of PPP waste-to-energy projects in China. Appl. Energy 2015, 158, 403-411. [CrossRef]

21. Song, J.; Song, D.; Zhang, X.; Sun, Y. Risk identification for PPP waste-to-energy incineration projects in China. Energy Policy 2013, 61, 953-962. [CrossRef]

22. Chou, J.-S.; Pramudawardhani, D. Cross-country comparisons of key drivers, critical success factors and risk allocation for public-private partnership projects. Int. J. Proj. Manag. 2015, 33, 1136-1150. [CrossRef]

23. Chan, A.P.C.; Lam, P.T.I.; Wen, Y.; Ameyaw, E.E.; Wang, S.; Ke, Y. Cross-Sectional Analysis of Critical Risk Factors for PPP Water Projects in China. J. Infrastruct. Syst. 2015, 21, 04014031. [CrossRef]

24. Ameyaw, E.E.; Chan, A.P.C. Evaluation and ranking of risk factors in public-private partnership water supply projects in developing countries using fuzzy synthetic evaluation approach. Expert Syst. Appl. 2015, 42, 5102-5116. [CrossRef]

25. Liu, T.; Wang, Y.; Wilkinson, S. Identifying critical factors affecting the effectiveness and efficiency of tendering processes in Public-Private Partnerships (PPPs): A comparative analysis of Australia and China. Int. J. Proj. Manag. 2016, 34, 701-716. [CrossRef]

26. Bing, L.; Akintoye, A.; Edwards, P.J.; Hardcastle, C. The allocation of risk in PPP/PFI construction projects in the UK. Int. J. Proj. Manag. 2005, 23, 25-35. [CrossRef]

27. Ding, X.-F.; Liu, H.-C. A 2-dimension uncertain linguistic DEMATEL method for identifying critical success factors in emergency management. Appl. Soft Comput. 2018, 71, 386-395. [CrossRef] 
28. Pandey, A.; Kumar, A. Commentary on "Evaluating the criteria for human resource for science and technology (HRST) based on an integrated fuzzy AHP and fuzzy DEMATEL approach". Appl. Soft Comput. 2017, 51, 351-352. [CrossRef]

29. Li, Y.; Hu, Y.; Zhang, X.; Deng, Y.; Mahadevan, S. An evidential DEMATEL method to identify critical success factors in emergency management. Appl. Soft Comput. 2014, 22, 504-510. [CrossRef]

30. Lin, C.-L.; Shih, Y.-H.; Tzeng, G.-H.; Yu, H.-C. A service selection model for digital music service platforms using a hybrid MCDM approach. Appl. Soft Comput. 2016, 48, 385-403. [CrossRef]

31. Kaddoura, K.; Zayed, T. An integrated assessment approach to prevent risk of sewer exfiltration. Sustain. Cities Soc. 2018, 41, 576-586. [CrossRef]

32. Bhatia, M.S.; Srivastava, R.K. Analysis of external barriers to remanufacturing using grey-DEMATEL approach: An Indian perspective. Resour. Conserv. Recycl. 2018, 136, 79-87. [CrossRef]

33. Quader, M.A.; Ahmed, S.; Raja Ghazilla, R.A.; Ahmed, S.; Dahari, M. Evaluation of criteria for CO2 capture and storage in the iron and steel industry using the 2-tuple DEMATEL technique. J. Clean. Prod. 2016, 120, 207-220. [CrossRef]

34. Wang, S.; Wang, J.; Li, J.; Wang, J.; Liang, L. Policy implications for promoting the adoption of electric vehicles: Do consumer's knowledge, perceived risk and financial incentive policy matter? Transp. Res. Part Policy Pract. 2018, 117, 58-69. [CrossRef]

35. Kavishe, N.; Jefferson, I.; Chileshe, N. An analysis of the delivery challenges influencing public-private partnership in housing projects: The case of Tanzania. Eng. Constr. Archit. Manag. 2018, 25, 202-240. [CrossRef]

36. Jin, X.-H.; Zhang, G. Modelling optimal risk allocation in PPP projects using artificial neural networks. Int. J. Proj. Manag. 2011, 29, 591-603. [CrossRef]

37. Keers, B.B.M.; van Fenema, P.C. Managing risks in public-private partnership formation projects. Int. J. Proj. Manag. 2018, 36, 861-875. [CrossRef]

38. Xu, Y.; Sun, C.; Skibniewski, M.J.; Chan, A.P.C.; Yeung, J.F.Y.; Cheng, H. System Dynamics (SD) -based concession pricing model for PPP highway projects. Int. J. Proj. Manag. 2012, 30, 240-251. [CrossRef]

39. Zheng, W.; Li, B.; Song, D.-P. Effects of risk-aversion on competing shipping lines' pricing strategies with uncertain demands. Transp. Res. Part B Methodol. 2017, 104, 337-356. [CrossRef]

40. Hwang, B.-G.; Zhao, X.; Gay, M.J.S. Public private partnership projects in Singapore: Factors, critical risks and preferred risk allocation from the perspective of contractors. Int. J. Proj. Manag. 2013, 31, 424-433. [CrossRef]

41. Liu, H.-C.; You, X.-Y.; Xue, Y.-X.; Luan, X. Exploring critical factors influencing the diffusion of electric vehicles in China: A multi-stakeholder perspective. Res. Transp. Econ. 2017, 66, 46-58. [CrossRef]

42. Morrissey, P.; Weldon, P.; O'Mahony, M. Future standard and fast charging infrastructure planning: An analysis of electric vehicle charging behaviour. Energy Policy 2016, 89, 257-270. [CrossRef]

43. Heravi, G.; Hajihosseini, Z. Risk Allocation in Public-Private Partnership Infrastructure Projects in Developing Countries: Case Study of the Tehran-Chalus Toll Road. J. Infrastruct. Syst. 2012, 18, 210-217. [CrossRef]

44. Nguyen, D.A.; Garvin, M.J.; Gonzalez, E.E. Risk Allocation in U.S. Public-Private Partnership Highway Project Contracts. J. Constr. Eng. Manag. 2018, 144, 04018017. [CrossRef]

45. Li, J.P.; Chen, R.; Lee, J.; Rao, H.R. A case study of private-public collaboration for humanitarian free and open source disaster management software deployment. Decis. Support Syst. 2013, 55, 1-11. [CrossRef]

46. Camacho Alcocer, D.; Krams, B.; Körner, M.; Hantsch, F.; Martin, U.; Herzwurm, G. Electric Vehicles in Rural Demand-Responsive Systems: Findings of Two Demand Responsive Transport Projects for the Improvement of Service Provision. World Electr. Veh. J. 2018, 9, 32. [CrossRef]

47. Osei-Kyei, R.; Chan, A.P.C. Review of studies on the Critical Success Factors for Public-Private Partnership (PPP) projects from 1990 to 2013. Int. J. Proj. Manag. 2015, 33, 1335-1346. [CrossRef]

48. Sachs, T.; Tiong, R.; Qing Wang, S. Analysis of political risks and opportunities in public private partnerships (PPP) in China and selected Asian countries: Survey results. Chin. Manag. Stud. 2007, 1, 126-148. [CrossRef]

49. Vasudevan, V.; Prakash, P.; Sahu, B. Options Framework and Valuation of Highway Infrastructure under Real and Financial Uncertainties. J. Infrastruct. Syst. 2018, 24, 04018014. [CrossRef] 
50. Soares, J.; Sousa, T.; Morais, H.; Vale, Z.; Canizes, B.; Silva, A. Application-Specific Modified Particle Swarm Optimization for energy resource scheduling considering vehicle-to-grid. Appl. Soft Comput. 2013, 13, 4264-4280. [CrossRef]

51. Hrelja, R.; Rye, T.; Mullen, C. Partnerships between operators and public transport authorities. Working practices in relational contracting and collaborative partnerships. Transp. Res. Part Policy Pract. 2018, 116, 327-338. [CrossRef]

52. Martinez, L.; Herrera, F. A 2-tuple fuzzy linguistic representation model for computing with words. IEEE Trans. Fuzzy Syst. 2000, 8, 746-752. [CrossRef]

53. Asan, U.; Kadaifci, C.; Bozdag, E.; Soyer, A.; Serdarasan, S. A new approach to DEMATEL based on interval-valued hesitant fuzzy sets. Appl. Soft Comput. 2018, 66, 34-49. [CrossRef]

54. Wu, W.-W. Segmenting critical factors for successful knowledge management implementation using the fuzzy DEMATEL method. Appl. Soft Comput. 2012, 12, 527-535. [CrossRef]

(C) 2019 by the authors. Licensee MDPI, Basel, Switzerland. This article is an open access article distributed under the terms and conditions of the Creative Commons Attribution (CC BY) license (http://creativecommons.org/licenses/by/4.0/). 